\title{
Synthesis and Biological Evaluation of Spirocyclic Chromane Derivatives as a Potential Treatment of Prostate Cancer
}

\author{
Li Feng ${ }^{1,2,+}$, Shujia Yu ${ }^{2,+}$, Hai Wang ${ }^{2}$, Shengwei Yang ${ }^{2}$, Xue Li $^{2}$, Hongjuan Dai ${ }^{3}$, Liwen Zhao ${ }^{2, *}$, Cheng Jiang ${ }^{1, *}$ \\ and Yazhou Wang ${ }^{2, *}$
}

1 Department of Medicinal Chemistry, China Pharmaceutical University, Tongjiaxiang 24, Nanjing 210009, China; fengli@sanhome.com

2 Nanjing Sanhome Pharmaceutical Co. Ltd., No. 99, West Yunlianghe Road, Jiangning District, Nanjing 210049, China; yusj@sanhome.com (S.Y.); wanghai@sanhome.com (H.W.); yangsw@sanhome.com (S.Y.); lixueyf@sanhome.com (X.L.)

3 Quality Department, Aurovitas Pharma Taizhou Co. Ltd., Taizhou 225300, China; hhitdhj@sohu.com

* Correspondence: zhaolw@sanhome.com (L.Z.); jc@cpu.edu.cn (C.J.); wangyzyf@sanhome.com (Y.W.); Tel.: +86-25-81066791 (Y.W.)

+ These authors contributed equally.

check for updates

Citation: Feng, L.; Yu, S.; Wang, H.; Yang, S.; Li, X.; Dai, H.; Zhao, L.; Jiang, C.; Wang, Y. Synthesis and Biological Evaluation of Spirocyclic Chromane Derivatives as a Potential Treatment of Prostate Cancer. Molecules 2021, 26, 3162. https:// doi.org/10.3390/molecules26113162

Academic Editor: Maria José U. Ferreira

Received: 21 April 2021

Accepted: 20 May 2021

Published: 25 May 2021

Publisher's Note: MDPI stays neutral with regard to jurisdictional claims in published maps and institutional affiliations.

Copyright: (c) 2021 by the authors. Licensee MDPI, Basel, Switzerland. This article is an open access article distributed under the terms and conditions of the Creative Commons Attribution (CC BY) license (https:// creativecommons.org/licenses/by/ $4.0 /)$.

\begin{abstract}
As a significant co-activator involved in cell cycle and cell growth, differentiation and development, p300/CBP has shown extraordinary potential target in cancer therapy. Herein we designed new compounds from the lead compound A-485 based on molecular dynamic simulations. A series of new spirocyclic chroman derivatives was prepared, characterized and proven to be a potential treatment of prostate cancer. The most potent compound B16 inhibited the proliferation of enzalutamide-resistant 22Rv1 cells with an $\mathrm{IC}_{50}$ value of $96 \mathrm{nM}$. Furthermore, compounds B16-P2 displayed favorable overall pharmacokinetic profiles, and better tumor growth inhibition than A-485 in an in vivo xenograft model.
\end{abstract}

Keywords: p300/CBP; HAT inhibitors; antitumor activity

\section{Introduction}

The acetylation and deacetylation of histones is a kind of reversible post-translational modification (PTM), which plays an important role in the regulation of gene expression in eukaryotic cells and is the arena of epigenetics [1-3]. The modification of the highly flexible and modifiable $N$-terminus of histones changes the state of histones, leading to genetic information transmission such as chromatin formation, transcription and DNA replication [4].

Histone acetyltransferase (HAT) and histone deacetylase (HDAC) are capable of affecting acetylation and deacetylation of histones, whose recruitment and normal function is the key regulatory step for gene expression and the cell cycle [3]. Functional deficiency of these enzymes may result in numerous diseases including tumors [5-7]. E1A binding protein of $300 \mathrm{kDa}$ (p300) and CREB binding protein (CBP) are two main members of the HAT family. p300/CBP is involved in cell cycle progression and cell growth, differentiation and development, and is a significant co-activator [8-13]. By promoting histone acetylation to form an open chromatin structure, the transcription structure can be easily combined with chromatin to improve transcription activity $[1,14]$. Research showed that p300/CBP is highly expressed and activated in many different diseases, especially malignant tumor $[5,9,15,16]$. As a result, it is of great importance to develop p300/CBP inhibitors with high selectivity and potency [14-16].

Early exploration of HAT inhibitors included bisubstrate analogs and natural products, such as Lys-CoA (1) and anacardic acid (2) (Figure 1), which showed weak potency or poor selectivity $[17,18]$. Several inhibitors were discovered over time and C646 (3) became a commonly used tool molecule $[19,20]$. In 2017, Abbvie scientists discovered a potent and 
selective HAT inhibitor, A-485 (4), using high-throughput screening in silico and experimental optimization [21]. It competed with acetyl-CoA for the active site of p300, and selectively inhibited the proliferation of haematological and solid cancer cell lines, such as castration-resistant androgen receptor-positive prostate cancer [22,23]. In addition, A-485 also showed a certain positive effect on liver damage and metabolic diseases [24,25]. On the basis of A-485, Zhou et al. identified a preclinical candidate B026 (5) with excellent pharmacological properties with the assistance of artificial intelligence and further optimization [26]. In the past decade, several other HAT inhibitors 6-8 with excellent potency have been reported [27-31].<smiles>CC(=O)NC(CCCCNC(=O)C[Se]O[Na])C(=O)O</smiles>

1 (Lys-CoA)

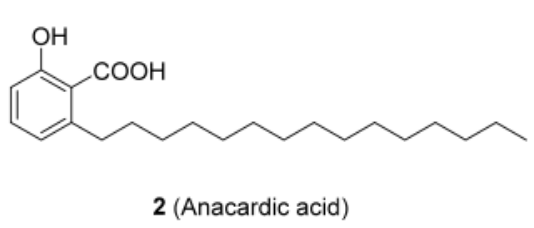

2 (Anacardic acid)<smiles>CC1=NN(c2ccc(C(=O)O)cc2)C(=O)/C1=C\c1ccc(-c2ccc(C)cc2[N+](=O)[O-])o1</smiles>

$3(\mathrm{C} 646)$<smiles>C[C@H](CN[C@H](C(=O)Nc1ccc(-c2cnn(C)c2)cn1)c1ccccc1)c1ccc(C#N)cc1</smiles>

$4(\mathrm{~A}-485)$<smiles>CCC(C)(C)OC(=O)c1cc(-c2cnn(C)c2)ccc1[C@]12CCc3cc(F)ccc3[C@@]1(C(=O)NCC(=O)C1Cc3cc(F)ccc3OC[C@H]1C(F)(F)F)CC2</smiles><smiles>CCNC(=O)c1ccc2c(C(=O)[C@@H](NC[C@H](C)c3ccc(C#N)cc3)c3ccccc3)c[nH]c2c1</smiles>

Figure 1. Representative small-molecule p300/CBP HAT inhibitors 1-8.

A-485 represents a significant breakthrough, but the cell potency still requires improvement. To better understand the binding mode of A485 and HAT domain, molecular dynamics studies were performed. To evaluate the quantitative contribution energy of the residues in the complex, the most practical MM-PBSA (GBSA) methods are employed [32-34]. The RMSD value of the protein backbone was calculated in a trajectory from 0 to $100 \mathrm{~ns}$. As shown in Figure 2A, dynamic equilibrium was attained after approximately $40 \mathrm{~ns}$ of simulation. The protein-ligand complex was converged to approximately $1.8 \AA$. Based on the relatively stable conformation, the two $\mathrm{N}$ atoms of methylurea group formed strong hydrogen bonds with Gln1455 and His1451 (Figure 2B,C). In contrast, the hydrogen bond between the carbonyl of spirocyclic lactam and Ser1400 became weaker after dynamics simulation (3.15 ̊ versus $2.94 \AA$ ). The 1,1,1-trifluoroisopropyl moiety was located in the lipophilic pocket formed by crucial Trp1466, together with Thr1411 and Pro1458. A large hydrophobic pocket formed by Val1401, His1451 and Pro1440 was also observed near the indenyl group. These two pockets offer sufficient imaginable space for molecular design. 
A

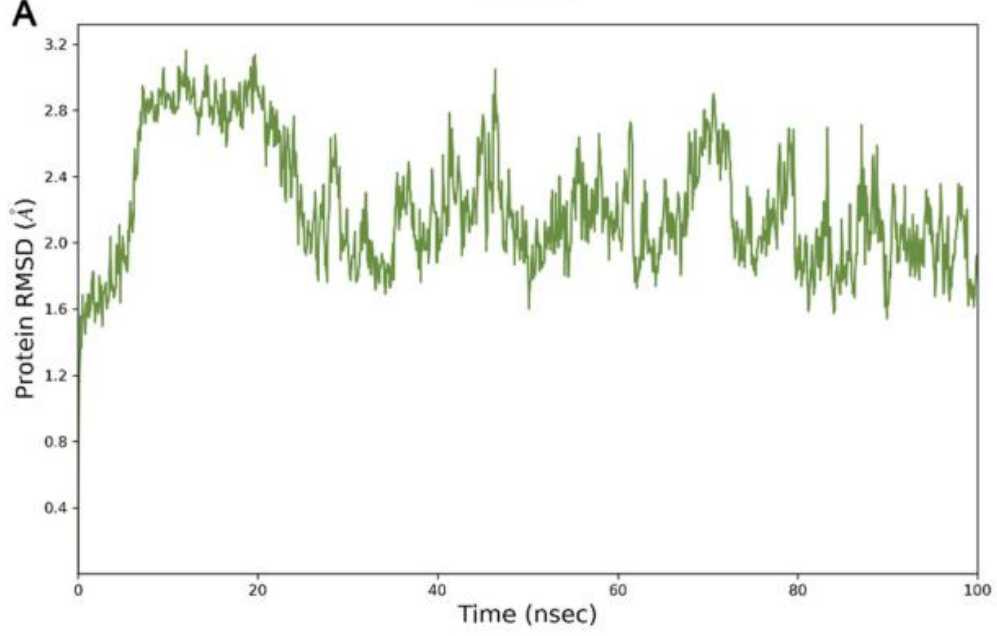

B Residue number

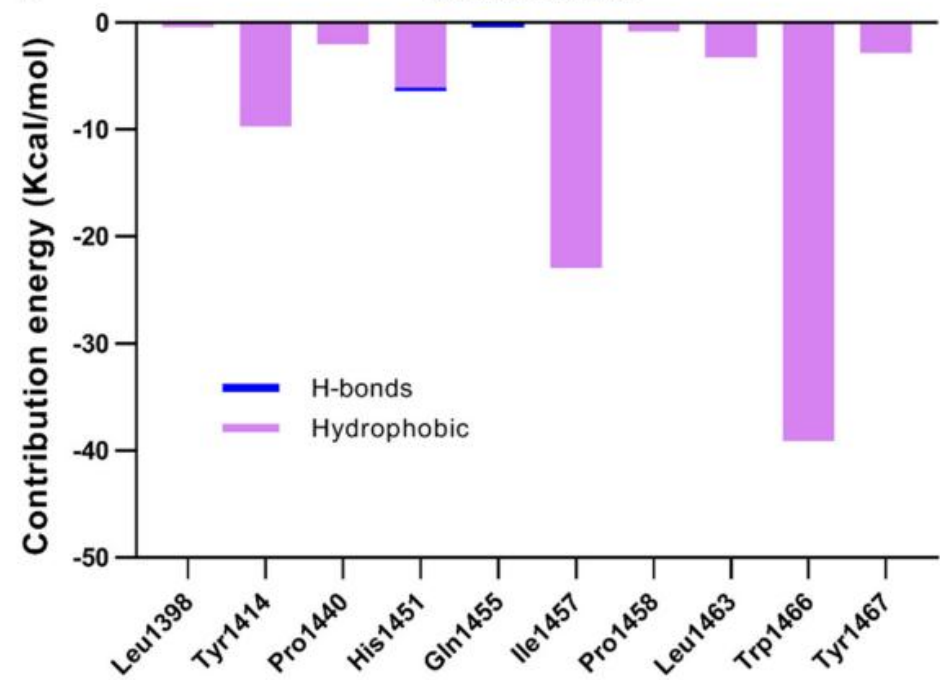

C $\quad$ Aara 462

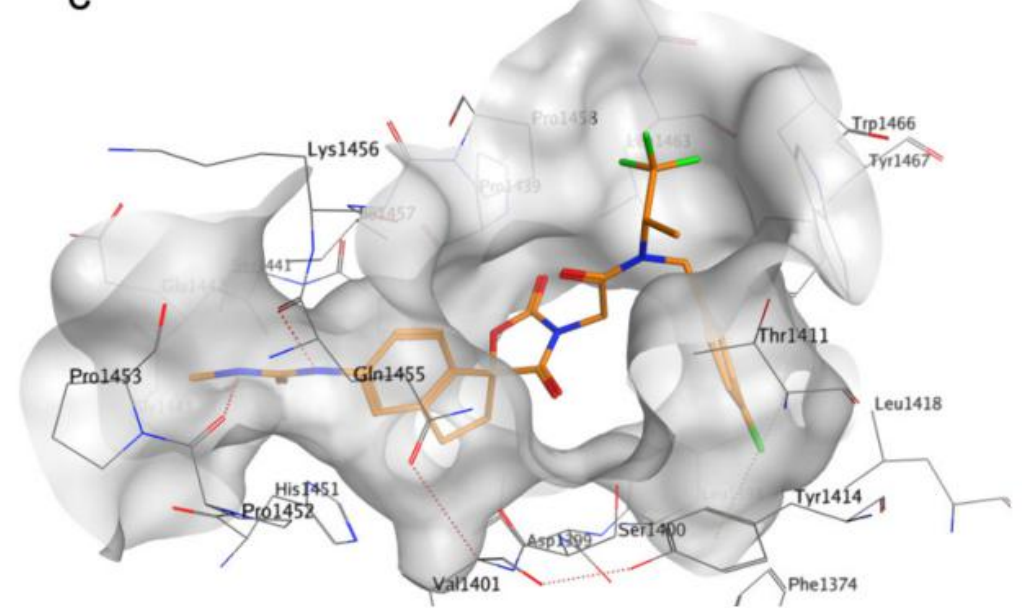

Figure 2. Molecular dynamics simulation and analysis of the interaction of A-485 with p300/CBP HAT domain. (A) RMSD of HAT backbone during the simulation time. (B) The residue contribution for protein-ligand interaction (blue: hydrogen bonds; purple: hydrophobic contacts). (C) Surface and interaction of the complex. (PDB code: $5 \mathrm{kj} 2$ ). 
Therefore, we designed several series of new compounds (Figure 3). First, phenyl or cyclopropyl groups were installed onto the indenyl to match the space and strengthen hydrophobicity. Second, a bioisosterism strategy was utilized in the spirocyclic core structure to acquire intellectual property, namely turning the carbamate into a lactam and the benzene into a pyridine. Finally, in consideration of the important hydrophobicity of Trp1466, we hypothesized that cyclization of the 1,1,1-trifluoroisopropyl and/or with the fluorobenzyl group based on conformational restriction strategy might benefit the affinity. The side chain of $\mathrm{R}$ group was expected to regulate the physicochemical properties.

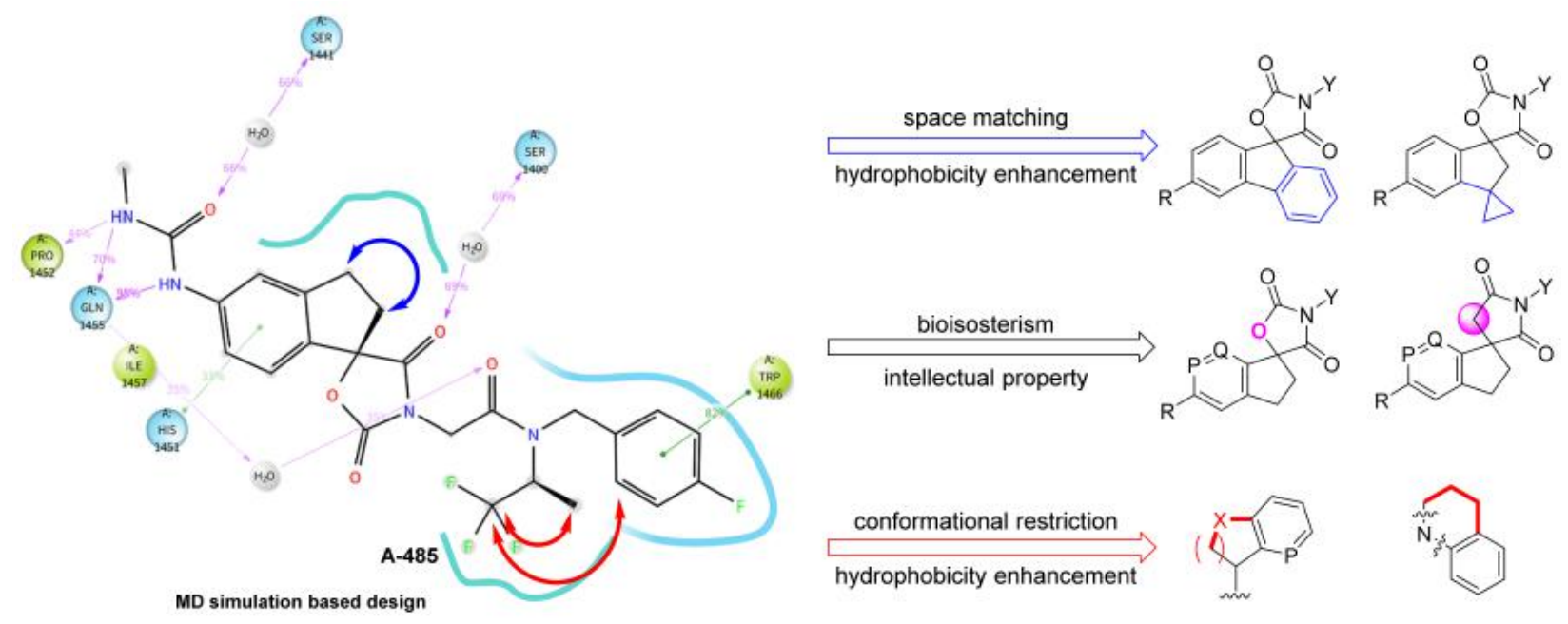

Figure 3. Current main design of new spirocyclic derivatives $(P, Q=C H, N)$.

\section{Results and Discussion}

\subsection{Chemistry}

As shown in Scheme 1, a series of spirocyclic chromane derivatives were prepared by similar methods, exemplified by B16. The remaining synthetic routes are detailed in the Supplementary Material. Starting from commercially available indanone, treatment with trimethylsilyl cyanide and $N$-methylmorpholine $N$-oxide afforded 5-bromo1-((trimethylsilyl)oxy)-2,3-dihydro- $1 H$-indene-1-carbonitrile (10). Treatment with acetyl chloride produced compound 11, which was cyclized with triphosgene and triethylamine to afford core structure 12. Reaction of (S)-chroman-4-amine (13) with 4-fluorobenzyl bromide gave 14, then acylation with bromoacetyl bromide afforded amide 15. Finally, nucleophilic substitution of this $\alpha$-bromoamide gave 16, and Pd-catalyzed Suzuki coupling with a pyrazolyl borate ester afforded B-16.

\subsection{In Vitro Antiproliferative Activities: Structure-Activity Relationship Study}

22Rv1 cells was chosen to evaluate the bioactivity in vitro, due to its AR-dependence but proliferation in the absence of androgens, and expression of a high level of AR-V7 variants. It was also representative of enzalutamide-resistant castration-resistant prostate cancer and unmet medical need furthermore [35,36]. As shown in Table 1, introducing a phenyl on the indenyl ring proved to be unsatisfactory, given the loss of antiproliferation activity in A1, indicating that this cavity is not large enough to accommodate the benzene ring. Attachment of smaller rings such as cyclopropyl (compound A2) was tolerated, showing comparable antiproliferation activity, but modification of the side chain led to decreased potency (compound A3). We also sought to construct an oxa-containing six-membered ring between the methylpyrazole and the benzene ring to restrict conformation (compound A4), but potency was lost. It was noteworthy that the dihedral angle between the indenyl and the urea moiety of A-486 was obviously bigger after dynamics simulation $\left(54.9^{\circ}\right.$ versus $27.6^{\circ}$ ), consistent with its lack of activity. Finally, changing the carbamate into a lactam (A5, A6) or benzene to pyridine $(\mathbf{A 7}, \mathbf{A 8})$ led to sharp decreases in potency. This was likely 
due to two subtle interactions, namely edge to face $\pi-\pi$ stacking betwen the indenyl and His1451, and hydrogen bond between the carbamate carbonyl and Ser1400, respectively.<smiles>CCOC(=N)[C@]1(O)CCc2cc(Br)ccc21</smiles><smiles>Cc1ccc(CNC2CCOc3ccccc32)cc1CNC1CCOc2ccccc21</smiles><smiles>CNC(=O)Cn1cc(-c2ccc3c(c2)CCC32OC(=O)N(CC(=O)N(Cc3ccc(F)cc3)C3CCOc4ccccc43)C2=O)cn1</smiles>

Scheme 1. Reagents and conditions: (a) TMSCN, NMO, acetonitrile, $60{ }^{\circ} \mathrm{C}, 81 \%$; (b) $\mathrm{AcCl}, \mathrm{EtOH}, 76 \%$; (c) 1-(bromomethyl)-4fluorobenzene, trifluoroacetic acid, triphosgene, $\mathrm{THF}, 10{ }^{\circ} \mathrm{C}, 93 \%$; (d) $\mathrm{K}_{2} \mathrm{CO}_{3}, \mathrm{DMF}, 30^{\circ} \mathrm{C}, 47 \%$; (e) bromoacetyl bromide, methylene chloride, $39 \%$; (f) $\mathrm{K}_{2} \mathrm{CO}_{3}$, DMF, $42 \%$; (g) Pd(dppf) $\mathrm{Cl}_{2}, \mathrm{NaHCO}_{3}, 1,4$-dioxane, $85{ }^{\circ} \mathrm{C}$, $33 \%$.

Table 1. 22Rv1 cell antiproliferation activity on optimization of core scaffolds a

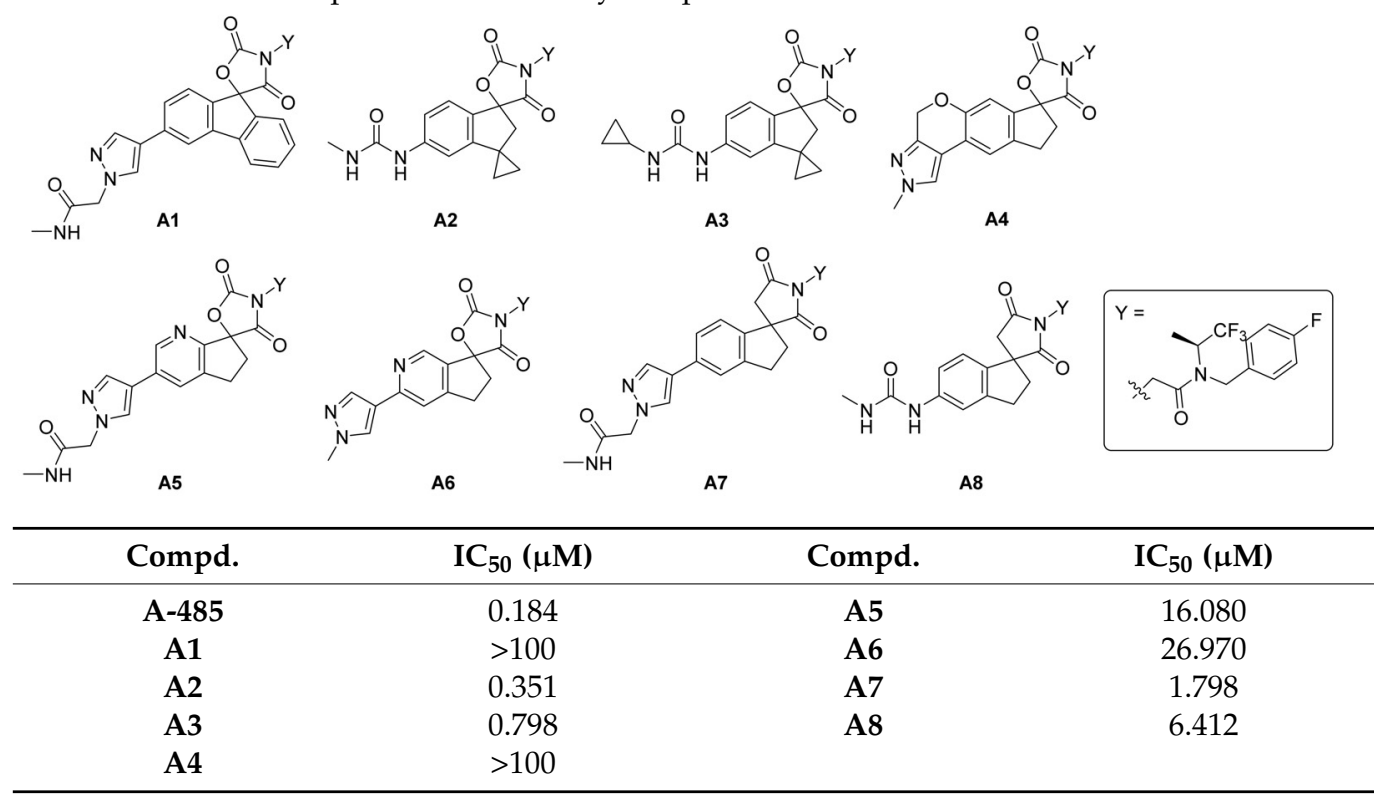

${ }^{a}$ Values are means of two independent experiments $(n=2)$. 
To optimize these spirocyclic chromane derivatives further, we turned our attention toward the third series of designs. As shown in Table 2, three substituents $\mathrm{R}^{1}, \mathrm{R}^{2}$, and $\mathrm{R}^{3}$ were systematically investigated to further explore the structure-activity relationships. Changing fluorophenyl to 2,2-difluorobenzo[d][1,3] dioxole (B1) led to 10-fold less potency than A-485. A two bridged ring was also incompatible (compounds B2, B3), indicating that the size and rigidity of the ring had a significant effect on the potency. When the 1,1,1trifluoroisopropyl group was displaced by an indenyl, several side chains were tolerated (compounds B4-B7), which confirmed our hypothesis of their regulatory effect on the physicochemical properties. Then an acetamide pyrazolyl was added to explore the displacement of 1,1,1-trifluoroisopropyl and 4-F-benzyl (B8-B16). An indenyl 5-position fluorine, 4-position pyridylation, and F-pyridylation of $\mathrm{R}^{3}$, all led to a 5-fold increased potency (cf. B11, B12 versus B10). The activity was getting stronger along the trend of 4,5,6,7-tetrahydro- $1 H$-indazole, 1,2,3,4-tetrahydronaphthalene and chromane (compounds B14-B16). B16 exhibited 2-fold more potency than A-485. Combining $R^{2}$ and $R^{3}$ into one group seemed to be another way to get a new series of molecules, so B17 and B18 were designed, but the bioactivity was reduced dramatically, likely due to mismatch of the hydrophobic pocket.

Table 2. Effect of optimization of R1, R2 and R3 on 22Rv1 cell antiproliferation activity ${ }^{\mathrm{a}}$.<smiles>[R7]c1ccc2c(c1)CCC21OC(=O)N(CC(=O)N([R])[R])C1=O</smiles>

\begin{tabular}{|c|c|c|c|c|}
\hline Compd. & $\mathbf{R}^{1}$ & $\mathbf{R}^{2}$ & $\mathbf{R}^{3}$ & $\mathrm{IC}_{50}(\mu \mathrm{M})$ \\
\hline$A-485^{b}$ & & & & 0.184 \\
\hline$B 1^{b}$ & & & & 1.369 \\
\hline$B 2^{b}$ & & & & 37.620 \\
\hline B3 & & & & $>25$ \\
\hline B4 & & & & 0.252 \\
\hline B5 & & & & 0.406 \\
\hline B6 & & & & 0.431 \\
\hline
\end{tabular}


Table 2. Cont.

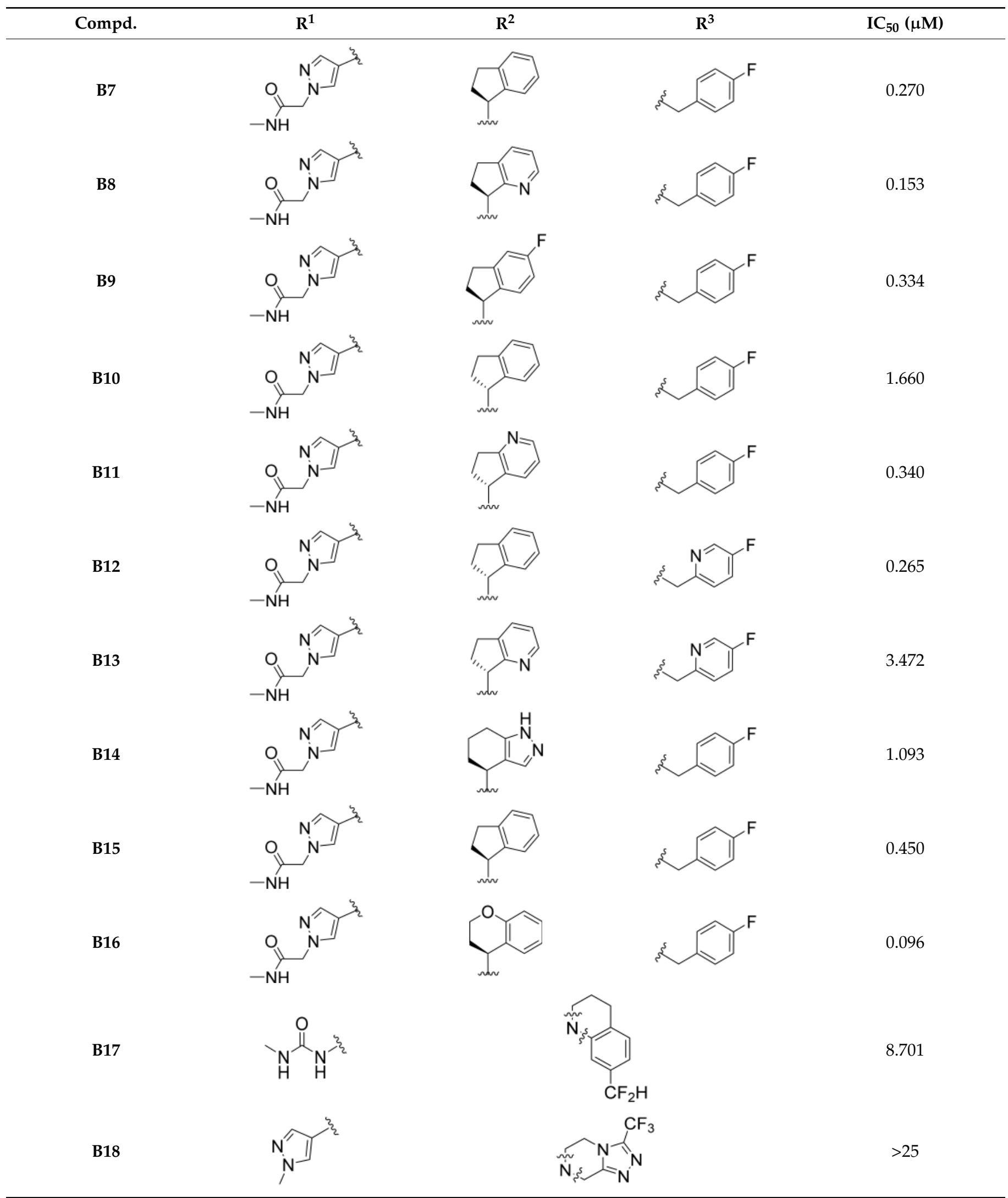

${ }^{\mathrm{a}}$ Values are means of two independent experiments $(n=2) .{ }^{\mathrm{b}}$ Spiro chirality has an $R$-configuration. 


\subsection{Pharmacokinetic Evaluation of Compounds $\mathbf{B} 8$ and $\mathbf{B} 16$}

In order to evaluate the druggability of these newly synthesized chromane derivatives, a pharmacokinetic test was performed on several potent compounds (Table 3). After administering $10 \mathrm{mg} / \mathrm{kg}$ orally to mice the half-life of $\mathbf{B} 8$ reached $23.9 \mathrm{~h}$. The lower plasma concentration of $\mathbf{B 8}$ was probably attributable to the much larger volume of distribution $\left(\mathrm{V}_{\mathrm{ss}}=13.2 \mathrm{~h} \cdot \mathrm{ng} / \mathrm{mL}\right)$. Compound $\mathbf{B} 16$ showed an modest clearance rate $(\mathrm{Cl}=1.8 \mathrm{~L} / \mathrm{h} / \mathrm{kg})$, volume of distribution (Vss $=1.0 \mathrm{~h} \cdot \mathrm{ng} / \mathrm{mL}$ ) and good oral bioavailability $(\mathrm{F}=33.2 \%)$. Due to the fact p300/CBP are ubiquitously expressed and involved in modulating immune responses [37], the plasma exposure of epigenetic regulator would be moderately controlled. Thus the pharmacokinetic profile of B16 met the criteria of druggability.

Table 3. Pharmacokinetic profiles of selected compounds ${ }^{\mathrm{a}}$.

\begin{tabular}{|c|c|c|c|c|c|c|c|c|}
\hline \multirow[b]{2}{*}{ Compd. } & \multicolumn{4}{|c|}{ IV. (1 mg/kg) } & \multicolumn{4}{|c|}{ PO. (10 mg/kg) } \\
\hline & $\begin{array}{c}T_{1 / 2} b \\
(h)\end{array}$ & $C_{L}^{c}(L / h / k g)$ & $\begin{array}{c}V_{\text {ss }(0-24 h)} \\
d(h * n g / m L)\end{array}$ & $\begin{array}{l}\mathrm{AUC}_{(0-24 h)} \\
(\mathrm{h} * \mathrm{ng} / \mathrm{mL})\end{array}$ & $\begin{array}{l}T_{1 / 2} \\
(h)\end{array}$ & $\underset{(\mathrm{ng} / \mathrm{mL})}{\mathrm{C}_{\max } \mathrm{e}}$ & $\begin{array}{c}\text { AUC } \\
(0-24 \mathrm{~h})(\mathrm{h} * \mathrm{ng} / \mathrm{mL})\end{array}$ & $F^{f}(\%)$ \\
\hline B8 & $17.0 \pm 4.9$ & $1.1 \pm 0.1$ & $13.2 \pm 4.2$ & $766.5 \pm 71.2$ & $23.9 \pm 3.6$ & $878.3 \pm 94.3$ & $1656 \pm 293.9$ & $21.6 \pm 3.8$ \\
\hline B16 & $0.5 \pm 0.0$ & $1.8 \pm 0.1$ & $1.0 \pm 0.1$ & $535.9 \pm 18.1$ & $1.6 \pm 0.3$ & $759.3 \pm 76.5$ & $1779.3 \pm 158.3$ & $33.2 \pm 3.0$ \\
\hline A-485 & $0.7 \pm 0.1$ & $0.5 \pm 0.1$ & $0.5 \pm 0.1$ & $1995.9 \pm 597.7$ & $3.1 \pm 1.1$ & $2700 \pm 518.8$ & $10,796.7 \pm 1493.0$ & $54.1 \pm 7.5$ \\
\hline
\end{tabular}

${ }^{\mathrm{a}}$ Values are means of three independent experiments $(n=3) .{ }^{\mathrm{b}}$ Half-life. ${ }^{\mathrm{c}}$ Clearance. ${ }^{\mathrm{d}}$ Volume of distribution at steady state. ${ }^{\mathrm{e}}$ Maximum concentration observed. ${ }^{\mathrm{f}}$ Oral bioavailability, $*$ means multiplication sign.

Considering B16 was a racemic mixuture, we carried out phsical resolution by chiral HPLC and further investigated by 22Rv1 cell antiproliferation and pharmacokinetics profiles (Table 4). However, both B16-P1 and B16-P2 were identical and comparable to the racemate B16. Based on their higher maximal inhibitory efficiency (TOP value, Emax) of cell proliferation and availability, B16-P2 was chosen for further study.

Table 4. 22Rv1 cell antiproliferation and pharmacokinetic profiles of two isomers of B16 ${ }^{\mathrm{a}}$.

\begin{tabular}{|c|c|c|c|c|c|c|}
\hline \multirow[b]{2}{*}{ Compd. } & \multicolumn{2}{|c|}{ 22Rv1 Cell } & \multicolumn{4}{|c|}{ Pharmacokinetics, PO. (10 mg/kg) } \\
\hline & $\mathrm{IC}_{50}(\mu \mathrm{M})$ & TOP (\%) & $\mathrm{T}_{1 / 2}(\mathrm{~h})$ & $\underset{(\mathrm{ng} / \mathrm{mL})}{\mathrm{C}_{\max }}$ & $\begin{array}{l}\mathrm{AUC}_{(0-24 h)} \\
(\mathrm{h} * \mathbf{n g} / \mathrm{mL})\end{array}$ & $\begin{array}{c}\operatorname{MRT}_{(0-24 ~ h)} \\
\text { (h) }\end{array}$ \\
\hline B16-P1 & 0.150 & 80.6 & $0.9 \pm 0.1$ & $488.3 \pm 139.3$ & $951.9 \pm 386.1$ & $1.2 \pm 0.3$ \\
\hline B16-P2 & 0.149 & 87.8 & $1.2 \pm 0.1$ & $428.0 \pm 66.7$ & $694.6 \pm 166.1$ & $1.3 \pm 0.1$ \\
\hline
\end{tabular}

${ }^{a}$ Values are means of two independent experiments (cell antiproliferation, $\left.n=2\right)$ and three independent experiments $(\mathrm{PK}, n=3)$, $*$ means multiplication sign.

\subsection{Anti-Tumor Efficacy of Compound B16-P2 In Vivo}

The anti-tumor activity of B16-P2 was then evaluated in vivo, using a 22Rv1 xenograft model (Figure 4). All compounds were administered orally once daily for 15 days, with A-485 as a reference. A statistically significant tumor growth delay was observed in the B16-P2 group $(p<0.05)$. At the same dosage of $80 \mathrm{mg} / \mathrm{kg}, \mathbf{B} 16-\mathbf{P 2}$ showed stronger efficacy than A-485 (tumor growth inhibition rate $=42 \%$ versus $35 \%$ ), thus confirming our aforementioned conclusion that the plasma exposure was not a decisive factor. During the study period, B16-P2 was well tolerated, and no death or significant loss of body weight was observed. 

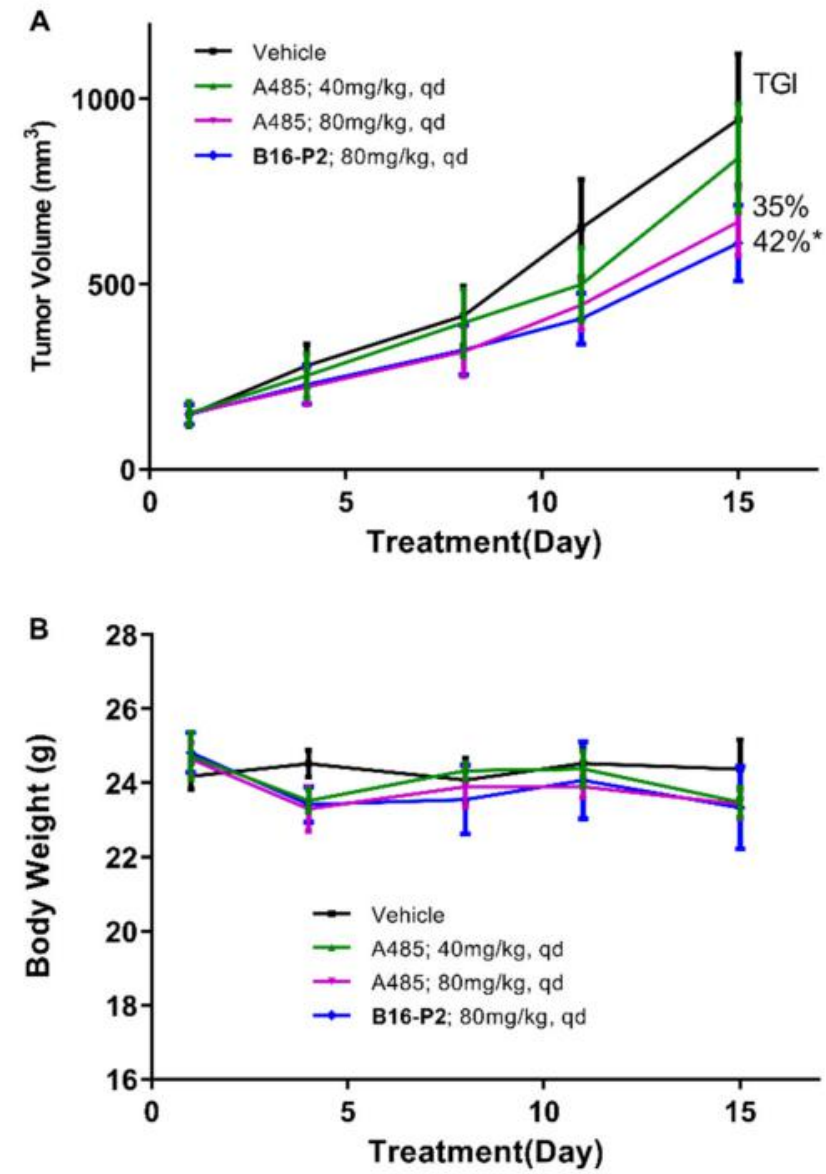

Figure 4. In vivo 22Rv1 xenograft model study of compound B16-P2 and A-485. (A) The tumor growth curve of four groups. (B) The body weights of mice over time ( $n=6,{ }^{*} p<0.05$ versus control).

\subsection{Molecular Docking Study of Compound B16}

To explore the possible binding mode and rationalize the observed potency of spirocyclic chromane derivative B16, molecular docking with p300 HAT domain was performed using a single isomer of spiro chirality (Figure 5). These two structures overlapped well with structural maintenance of two key hydrogen bonds: carbonyl of the oxazolidinedione and Ser1400, C-H ... $\pi$ between 4-F-phenyl and Leu1398. In the side chain region, $\mathrm{N}$-methyl-2-(1H-pyrazol-1-yl)acetamide of B16 formed $\mathrm{NH} \ldots$ O hydrogen bond with Gln1455 and C-H . . $\pi$ bond with His1451, while two equivalent hydrogen bonds formed between methylurea of A-485 and the carbonyl of Gln1455. Importantly, an additional hydrogen bond was observed between the chromane oxygen of B16 and Arg1462, which might contribute to the improved activity. Thus this series of spirocyclic chromane derivatives exemplified by B16 might act as p300 HAT inhibitors. 


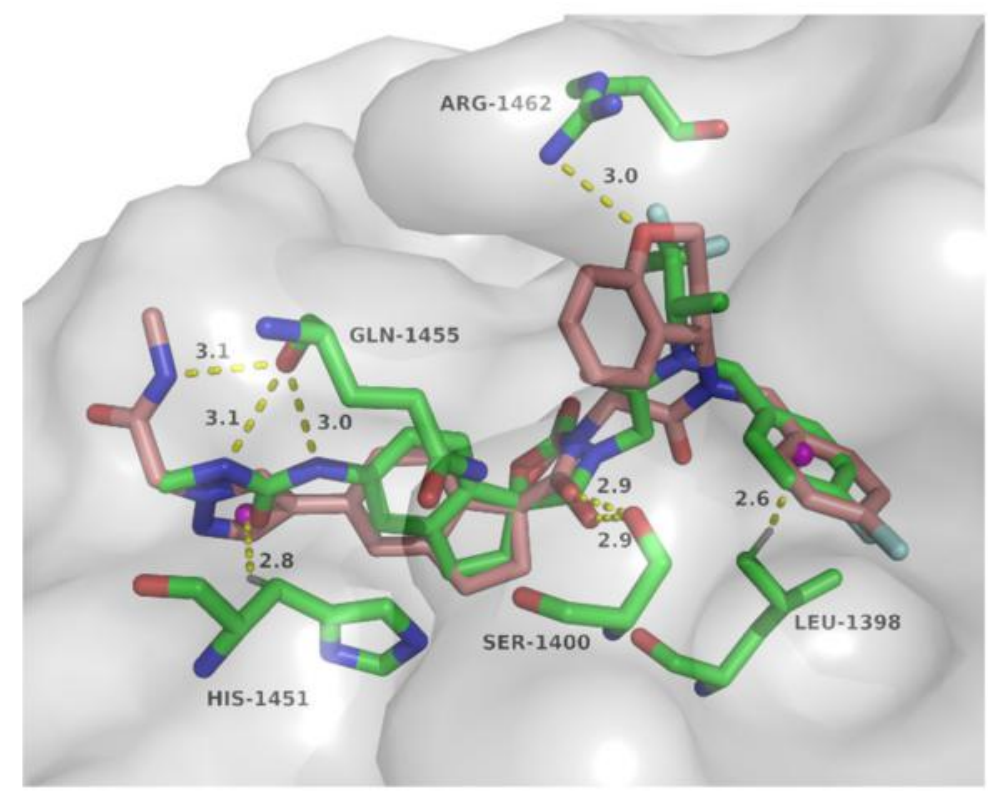

Figure 5. Docking mode of compound B16 (coppery) with p300 HAT domain overlapping with A-485 (green) (PDB code: 5kj2).

\section{Materials and Methods}

\subsection{Chemistry}

Generally, unless otherwise specified, the starting materials were purchased commercially and used directly without further purification. All reactions were monitored by thin layer chromatography (TLC) on silica gel plates (HSGF254), and the components were visualized using ultraviolet light or phosphomolybdic acid. Concentration under vacuum means rotary evaporation under reduced pressure at $35-40{ }^{\circ} \mathrm{C}$. Use silica gel (200-300 mesh) for flash column chromatography. The ${ }^{1} \mathrm{H}-\mathrm{NMR}$ and ${ }^{13} \mathrm{C}-\mathrm{NMR}$ spectra were collected on a $400 \mathrm{MHz}$ spectrometer (Bruker, MS, USA). HPLC conditions: Column: Xselect CSH C $18(4.6 \times 150 \mathrm{~mm}, 3.5 \mu \mathrm{m}), 30^{\circ} \mathrm{C}_{;} \mathrm{CH}_{3} \mathrm{CN} / \mathrm{H}_{2} \mathrm{O}$ (containing $0.1 \% \mathrm{CF}_{3} \mathrm{COOH}$ ) eluent, $10 \% \mathrm{CH}_{3} \mathrm{CN}$ (kept for $2 \mathrm{~min}$ ) to $90 \% \mathrm{CH}_{3} \mathrm{CN}$, gradient $13 \mathrm{~min}$, then kept for $3 \mathrm{~min}$; Flow rate: $1.2 \mathrm{~mL} / \mathrm{min}$; Detection: UV $254 \mathrm{~nm}$; unless otherwise stated.

3.1.1. N-(4-Fluorobenzyl)-2-(3-(1-(2-(methylamino)-2-oxoethyl)-1H-pyrazol-4-yl)-2' , 4' dioxospiro[fluorene-9,5'-oxazolidin]-3'-yl)-N-((S)-1,1,1-trifluoropropan-2-yl)acetamide (A1)

Prepared using the same procedure as for A4, except using 2-(3-bromo-2' $4^{\prime}$-dioxospiro [fluorene-9, $5^{\prime}$-oxazolidin]-3'-yl)- $N$-(4-fluorobenzyl)- $N-((S)-1,1,1$-trifluoropropan-2-yl) acetamide $(76,0.23 \mathrm{~g}, 0.39 \mathrm{mmol})$ instead of 77 and using $N$-methyl-2-(4-(4,4,5,5-tetramethyl1,3,2-dioxaborolan-2-yl)-1H-pyrazol-1-yl) acetamide ( $0.16 \mathrm{~g}, 0.58 \mathrm{mmol})$ instead of 1-methyl4-(4,4,5,5-tetramethyl-1,3,2-dioxaborolan-2-yl)-1 $\mathrm{H}$-pyrazole afforded $\mathbf{A 1}(0.05 \mathrm{~g}, 20 \%) .{ }^{1} \mathrm{H}$ $\operatorname{NMR}\left(\mathrm{CDCl}_{3}\right) \delta 7.93(\mathrm{~s}, 1 \mathrm{H}), 7.78(\mathrm{~s}, 1 \mathrm{H}), 7.73(\mathrm{~s}, 1 \mathrm{H}), 7.69(\mathrm{~d}, J=7.4 \mathrm{~Hz}, 1 \mathrm{H}), 7.60(\mathrm{~d}$, $J=7.6 \mathrm{~Hz}, 2 \mathrm{H}), 7.54(\mathrm{~d}, J=7.2 \mathrm{~Hz}, 1 \mathrm{H}), 7.51-7.46(\mathrm{~m}, 1 \mathrm{H}), 7.45-7.39(\mathrm{~m}, 1 \mathrm{H}), 7.39-7.33$ $(\mathrm{m}, 1 \mathrm{H}), 7.29(\mathrm{~s}, 2 \mathrm{H}), 7.10(\mathrm{t}, J=8.1 \mathrm{~Hz}, 2 \mathrm{H}), 6.29(\mathrm{~s}, 1 \mathrm{H}), 5.65-5.42(\mathrm{~m}, 1 \mathrm{H}), 4.83(\mathrm{~d}$, $J=12.1 \mathrm{~Hz}, 3 \mathrm{H}), 4.69(\mathrm{~m}, 2 \mathrm{H}), 4.54(\mathrm{~d}, J=16.4 \mathrm{~Hz}, 1 \mathrm{H}), 4.32(\mathrm{~d}, J=16.4 \mathrm{~Hz}, 1 \mathrm{H}), 2.82(\mathrm{~d}$, $J=4.4 \mathrm{~Hz}, 3 \mathrm{H}), 1.32(\mathrm{~d}, J=7.0 \mathrm{~Hz}, 3 \mathrm{H}) .{ }^{13} \mathrm{C}-\mathrm{NMR}\left(\mathrm{CDCl}_{3}\right) \delta 171.74,167.43,166.75,162.37$ $(\mathrm{d}, J=245 \mathrm{~Hz}), 155.06,142.48,141.37,141.19,138.91,137.05,136.96,135.22,131.52,131.35$, $129.06,128.48,127.26,127.18,126.04,122.15$ (q, $J=262 \mathrm{~Hz}), 120.87,117.89,116.51,116.30$, $106.73,90.87,55.30,50.69,50.39,46.03,42.35,26.29,11.52$. HPLC: retention time $12.997 \mathrm{~min}$, $96.51 \%$ purity (using an XBridge $\mathrm{C}_{18}$ column $(4.6 \times 150 \mathrm{~mm}, 3.5 \mu \mathrm{m})$ instead of an Xselect $\mathrm{CSH} \mathrm{C}_{18}$ one $(4.6 \times 150 \mathrm{~mm}, 3.5 \mu \mathrm{m})$, and ammonia instead of trifluoroacetic acid). HRMS (ESI): $\mathrm{m} / z$ calcd for $\mathrm{C}_{33} \mathrm{H}_{27} \mathrm{~F}_{4} \mathrm{~N}_{5} \mathrm{O}_{5}, 650.2021$, found $650.2030[\mathrm{M}+\mathrm{H}]^{+}$. 
3.1.2. $\mathrm{N}$-(4-Fluorobenzyl)-2-(5'-(3-methylureido)-2" ${ }^{\prime \prime} 4^{\prime \prime}$-dioxo-2' $H$-dispiro[cyclopropane1,3'-indene-1', , $^{\prime \prime}$-oxazolidin]-3' ${ }^{\prime \prime}$-yl)- $N$-((S)-1,1,1-trifluoropropan-2-yl)acetamide (A2)

To a solution of 2-(5'-amino-2 $2^{\prime \prime}, 4^{\prime \prime}$-dioxo-2 ${ }^{\prime} H$-dispiro[cyclopropane-1, $3^{\prime}$-indene- $1^{\prime}, 5^{\prime \prime}$ oxazolidin]-3"'-yl)- $N$-(4-fluorobenzyl)- $N-((S)-1,1,1$-trifluoropropan-2-yl) acetamide (79, $0.13 \mathrm{~g}$, $0.26 \mathrm{mmol})$ and triethylamine $(0.10 \mathrm{~g}, 1.00 \mathrm{mmol})$ in anhydrous tetrahydrofuran $(2 \mathrm{~mL})$ was added triphosgene $(0.08 \mathrm{~g}, 0.26 \mathrm{mmol})$. The mixture was stirred for $30 \mathrm{~min}$ at room temperature. Then methylamine in tetrahydrofuran $(2 \mathrm{M}, 1.3 \mathrm{~mL})$ was added and the mixture was stirred for $1 \mathrm{~h}$. A saturated solution of sodium bicarbonate was added. The mixture was extracted with ethyl acetate. The organic phase was combined, dried over anhydrous $\mathrm{Na}_{2} \mathrm{SO}_{4}$, and concentrated under vacuum. The residue was purified by silica gel column chromatography (EA:PE $=1: 1)$ to afford A2 $(0.10 \mathrm{~g}, 69 \%) .{ }^{1} \mathrm{H}-\mathrm{NMR}\left(\mathrm{CDCl}_{3}\right)$ $\delta 7.28(\mathrm{~s}, 2 \mathrm{H}), 7.24-7.18(\mathrm{~m}, 1 \mathrm{H}), 7.11(\mathrm{t}, J=8.2 \mathrm{~Hz}, 2 \mathrm{H}), 7.03(\mathrm{~d}, J=8.7 \mathrm{~Hz}, 1 \mathrm{H}), 6.71$ $(\mathrm{m}, 1 \mathrm{H}), 5.52-5.38(\mathrm{~m}, 1 \mathrm{H}), 5.23(\mathrm{~m}, 1 \mathrm{H}), 4.78-4.56(\mathrm{~m}, 1 \mathrm{H}), 4.43(\mathrm{~m}, 1 \mathrm{H}), 4.21(\mathrm{~m}, 1 \mathrm{H})$, $2.91-2.80(\mathrm{~m}, 1 \mathrm{H}), 2.73(\mathrm{~d}, J=4.2 \mathrm{~Hz}, 2 \mathrm{H}), 2.40(\mathrm{~d}, J=14.3 \mathrm{~Hz}, 1 \mathrm{H}), 1.32(\mathrm{~d}, J=6.8 \mathrm{~Hz}, 3 \mathrm{H})$, $1.02(\mathrm{~s}, 4 \mathrm{H}) .{ }^{13} \mathrm{C}-\mathrm{NMR}\left(\mathrm{CDCl}_{3}\right) \delta 174.40,167.21,162.35(\mathrm{~d}, \mathrm{~J}=245 \mathrm{~Hz}), 156.31,154.54,151.60$, $142.51,131.35,130.34,127.21,125.24(\mathrm{q}, J=276 \mathrm{~Hz}), 124.70,118.39,116.51,116.30,109.63$, 93.65, 46.09, 44.58, 41.80, 40.02, 29.72, 26.74, 25.09, 20.71, 17.57, 11.51. HPLC: retention time $12.360 \mathrm{~min}, 96.04 \%$ purity. HRMS (ESI): $\mathrm{m} / \mathrm{z}$ calcd for $\mathrm{C}_{27} \mathrm{H}_{26} \mathrm{~F}_{4} \mathrm{~N}_{4} \mathrm{O}_{5}, 563.1912$, found $563.1924[\mathrm{M}+\mathrm{H}]^{+}$.

3.1.3. 2-(5'-(3-Cyclopropylureido)-2" ${ }^{\prime \prime} 4^{\prime \prime}$-dioxo-2' $H$-dispiro[cyclopropane-1, $3^{\prime}$-indene$1^{\prime}, 5^{\prime \prime}$-oxazolidin]-3"' -yl)- $N$-(4-fluorobenzyl)- $N-((S)-1,1,1$-trifluoropropan-2yl)acetamide (A3)

Prepared using the same procedure as for A2 to afford A3 (0.078 g, 51\%). ${ }^{1} \mathrm{H}-\mathrm{NMR}$ $\left(\mathrm{CDCl}_{3}\right) \delta 7.40-7.26(\mathrm{~m}, 3 \mathrm{H}), 7.14(\mathrm{~d}, J=2.5 \mathrm{~Hz}, 1 \mathrm{H}), 7.13-7.06(\mathrm{~m}, 2 \mathrm{H}), 7.01-6.88$ $(\mathrm{m}, 1 \mathrm{H}), 5.55-5.40(\mathrm{~m}, 1 \mathrm{H}), 5.34-5.23(\mathrm{~m}, 1 \mathrm{H}), 4.75-4.59(\mathrm{~m}, 2 \mathrm{H}), 4.46-4.40(\mathrm{~m}, 1 \mathrm{H})$, $4.21(\mathrm{t}, J=15.8 \mathrm{~Hz}, 1 \mathrm{H}), 2.89(\mathrm{dd}, J=14.3,8.7 \mathrm{~Hz}, 1 \mathrm{H}), 2.55(\mathrm{~s}, 1 \mathrm{H}), 2.42(\mathrm{~d}, J=14.3 \mathrm{~Hz}$, $1 \mathrm{H}), 1.31(\mathrm{~d}, J=6.9 \mathrm{~Hz}, 3 \mathrm{H}), 1.08-0.99(\mathrm{~m}, 4 \mathrm{H}), 0.78(\mathrm{~d}, J=5.5 \mathrm{~Hz}, 2 \mathrm{H}), 0.57(\mathrm{~s}, 2 \mathrm{H})$ ${ }^{13} \mathrm{C}-\mathrm{NMR}\left(\mathrm{CDCl}_{3}\right) \delta 174.14,167.06,162.34(\mathrm{~d}, J=246 \mathrm{~Hz}), 156.30,154.51,154.43,151.57$, $142.08,131.41,130.76,127.28,127.20,124.77,124.71,117.23$ (q, J = 205 Hz), 116.28, 109.54, $93.56,93.45,46.04,44.63,41.83,40.34,25.14,22.55,17.67,14.71,11.52,7.36$. HPLC: retention time $12.830 \mathrm{~min}, 97.90 \%$ purity. HRMS (ESI): $\mathrm{m} / z$ calcd for $\mathrm{C}_{29} \mathrm{H}_{28} \mathrm{~F}_{4} \mathrm{~N}_{4} \mathrm{O}_{5}, 589.2069$, found $589.2081[\mathrm{M}+\mathrm{H}]^{+}$.

3.1.4. N-(4-Fluorobenzyl)-2-(2-methyl-2', $4^{\prime}$-dioxo-2,4,8,9-tetrahydrospiro[cyclopenta [6,7]chromeno [3,4-c]pyrazole-7,5'-oxazolidin]-3'-yl)- $N-((S)-1,1,1$-trifluoropropan2-yl)acetamide (A4)

Prepared using the same procedure as for 77, except using 2-methyl-2,4,8,9tetrahydrospiro cyclopenta [6,7] chromeno [3,4-c]pyrazole-7, $5^{\prime}$-oxazolidine]-2' $4^{\prime}$-dione $(40,0.01 \mathrm{~g}, 0.03 \mathrm{mmol})$ instead of 28 afforded $\mathrm{A} 4(0.003 \mathrm{~g}, 19 \%) .{ }^{1} \mathrm{H}-\mathrm{NMR}\left(\mathrm{CDCl}_{3}\right) \delta 7.53(\mathrm{~s}$, $1 \mathrm{H}), 7.29(\mathrm{~s}, 2 \mathrm{H}), 7.21(\mathrm{~s}, 1 \mathrm{H}), 7.13(\mathrm{~d}, J=7.9 \mathrm{~Hz}, 1 \mathrm{H}), 7.09(\mathrm{~d}, J=8.7 \mathrm{~Hz}, 1 \mathrm{H}), 7.05-6.93(\mathrm{~m}$, $1 \mathrm{H}), 5.61-5.45(\mathrm{~m}, 1 \mathrm{H}), 5.22(\mathrm{~s}, 2 \mathrm{H}), 4.73-4.63(\mathrm{~m}, 2 \mathrm{H}), 4.43-4.39(\mathrm{~m}, 1 \mathrm{H}), 4.24-4.19$ $(\mathrm{m}, 1 \mathrm{H}), 3.93(\mathrm{~s}, 3 \mathrm{H}), 3.16(\mathrm{~s}, 1 \mathrm{H}), 3.11-2.98(\mathrm{~m}, 1 \mathrm{H}), 2.87-2.73(\mathrm{~m}, 1 \mathrm{H}), 2.60-2.48$ $(\mathrm{m}, 1 \mathrm{H}), 1.30(\mathrm{~d}, J=3.0 \mathrm{~Hz}, 3 \mathrm{H}) .{ }^{13} \mathrm{C}-\mathrm{NMR}\left(\mathrm{CDCl}_{3}\right) \delta 166.73,162.37(\mathrm{~d}, J=243 \mathrm{~Hz})$, $156.69,152.01,145.33,139.82,138.46,130.92,128.86,127.27,124.60,123.22,121.59,120.66$ (q, $J=287 \mathrm{~Hz}), 119.06,116.50,116.28,113.16,112.95,94.89,64.37,46.01,39.09,35.62,29.71$, 29.38, 22.70, 14.13. HPLC: retention time $13.194 \mathrm{~min}, 95.56 \%$ purity. HRMS (ESI): $\mathrm{m} / z$ calcd for $\mathrm{C}_{28} \mathrm{H}_{24} \mathrm{~F}_{4} \mathrm{~N}_{4} \mathrm{O}_{5}, 573.1753$, found $573.1763[\mathrm{M}+\mathrm{H}]^{+}$.

3.1.5. N-(4-Fluorobenzyl)-2-(3-(1-(2-(methylamino)-2-oxoethyl)-1H-pyrazol-4-yl)-2', $4^{\prime}$ dioxo-5,6-dihydrospiro[cyclopenta[b]pyridine-7, $5^{\prime}$-oxazolidin]-3'-yl)- $N-((S)-1,1,1-$ trifluoropropan-2-yl)acetamide (A5)

A solution of 2-(3-bromo-2',4'-dioxo-5,6-dihydrospiro[cyclopenta[b]pyridine-7,5'oxazolidin]-3'-yl)- $N$-(4-fluorobenzyl)- $N$-((S)-1,1,1-trifluoropropan-2-yl) acetamide (80, $0.27 \mathrm{~g}$, 
$0.50 \mathrm{mmol}), 1$-methyl-4-(4,4,5,5-tetra-methyl-1,3,2-dioxaborolan-2-yl)-1H-pyrazole ( $0.20 \mathrm{~g}$, $0.75 \mathrm{mmol})$, and $\mathrm{Pd}(\mathrm{dppf}) \mathrm{Cl}_{2}(0.04 \mathrm{~g}, 0.05 \mathrm{mmol})$ in a saturated solution of potassium bicarbonate $(0.5 \mathrm{~mL})$ and 1.4-dioxane $(5 \mathrm{~mL})$ was stirred in $85^{\circ} \mathrm{C}$ under nitrogen until completion. The mixture was cooled to room temperature and concentrated under vacuum. The residue was purified by silica gel column chromatography (EA:PE = 1:4) to afford A5 (0.07 g, 24\%). ${ }^{1} \mathrm{H}-\mathrm{NMR}\left(400 \mathrm{MHz}, \mathrm{CDCl}_{3}\right) \delta 8.70(\mathrm{~d}, J=6.0 \mathrm{~Hz}, 1 \mathrm{H}), 8.09(\mathrm{~s}, 1 \mathrm{H}), 8.03$ $(\mathrm{s}, 1 \mathrm{H}), 7.44(\mathrm{~s}, 1 \mathrm{H}), 7.29(\mathrm{~s}, 2 \mathrm{H}), 7.18-7.09(\mathrm{~m}, 2 \mathrm{H}), 6.23(\mathrm{~s}, 1 \mathrm{H}), 5.57-5.41(\mathrm{~m}, 1 \mathrm{H})$, $4.85(\mathrm{~s}, 2 \mathrm{H}), 4.74-4.63(\mathrm{~m}, 2 \mathrm{H}), 4.48-4.40(\mathrm{~m}, 1 \mathrm{H}), 4.33-4.28(\mathrm{~m}, 1 \mathrm{H}), 3.35-3.22(\mathrm{~m}$, $1 \mathrm{H}), 3.22-3.12(\mathrm{~m}, 1 \mathrm{H}), 2.86-2.85(\mathrm{~m}, 1 \mathrm{H}), 2.81(\mathrm{~d}, J=4.5 \mathrm{~Hz}, 4 \mathrm{H}), 2.65-2.57(\mathrm{~m}, 1 \mathrm{H})$, 1.33 (s, 3H). ${ }^{13} \mathrm{C}-\mathrm{NMR}\left(101 \mathrm{MHz}, \mathrm{CDCl}_{3}\right) \delta 167.32,167.07,162.36$ (d, J = $\left.218 \mathrm{~Hz}\right), 155.28$, $152.92,146.59,139.72,131.37,130.96,130.47,128.05(\mathrm{q}, J=161 \mathrm{~Hz}), 127.62,124.98,124.24$, $116.55,116.34,115.76,92.85,63.41,57.41,55.35,46.05,42.03,35.37,30.27,26.30,19.21,13.77$. HPLC: retention time $11.383 \mathrm{~min}, 98.74 \%$ purity. HRMS (ESI): $\mathrm{m} / z$ calcd for $\mathrm{C}_{28} \mathrm{H}_{26} \mathrm{~F}_{4} \mathrm{~N}_{6} \mathrm{O}_{5}$, 603.1974, found $603.1983[\mathrm{M}+\mathrm{H}]^{+}$.

3.1.6. $N$-(4-Fluorobenzyl)-2-(3-(1-methyl-1H-pyrazol-4-yl)-2' , $4^{\prime}$-dioxo-5,6-dihydrospiro [cyclopenta[c]pyridine-7, $5^{\prime}$-oxazolidin]-3'-yl)- $N-((S)-1,1,1-$ trifluoropropan-2yl)acetamide (A6)

Prepared using the same procedure as for $\mathbf{7 7}$ (see Supplementary Materials for details), except using 3-(1-methyl-1H-pyrazol-4-yl)-5,6-dihydrospiro[cyclopenta[c]pyridine-7,5'oxazolidine]-2' $4^{\prime}$-dione $(53,0.12 \mathrm{~g}, 0.42 \mathrm{mmol})$ instead of $\mathbf{7 6}$ afforded $\mathbf{A 6}(0.06 \mathrm{~g}, 24 \%)$. ${ }^{1} \mathrm{H}-\mathrm{NMR}\left(\mathrm{CDCl}_{3}\right) \delta 8.66(\mathrm{~d}, J=7.7 \mathrm{~Hz}, 1 \mathrm{H}), 7.94(\mathrm{~s}, 2 \mathrm{H}), 7.54(\mathrm{~s}, 1 \mathrm{H}), 7.42(\mathrm{~s}, 2 \mathrm{H}), 7.29(\mathrm{~s}$, $1 \mathrm{H}), 7.12(\mathrm{t}, J=7.9 \mathrm{~Hz}, 2 \mathrm{H}), 5.62-5.38(\mathrm{~m}, 1 \mathrm{H}), 4.76-4.59(\mathrm{~m}, 2 \mathrm{H}), 4.46-4.42(\mathrm{~m}, 1 \mathrm{H})$, $4.26-4.20(\mathrm{~m}, 1 \mathrm{H}), 3.95(\mathrm{~s}, 3 \mathrm{H}), 3.31-3.20(\mathrm{~m}, 1 \mathrm{H}), 3.19-3.10(\mathrm{~m}, 1 \mathrm{H}), 2.86-2.76(\mathrm{~m}$, 1H), $2.59(\mathrm{~s}, 1 \mathrm{H}), 1.32(\mathrm{~s}, 3 \mathrm{H}) .{ }^{13} \mathrm{C}-\mathrm{NMR}\left(\mathrm{CDCl}_{3}\right) \delta 173.53,166.66,162.38(\mathrm{~d}, J=245 \mathrm{~Hz})$, $155.08,153.82,146.39,137.73,136.89,131.30,131.27,129.56,127.27,127.19,124.95$ (q, $J=313 \mathrm{~Hz}), 116.52,116.31,115.41,114.19,92.98,46.03,41.96,39.24,38.95,35.41,30.21,11.52$. HPLC: retention time $11.922 \mathrm{~min}, 95.80 \%$ purity. HRMS (ESI): $\mathrm{m} / z$ calcd for $\mathrm{C}_{26} \mathrm{H}_{23} \mathrm{~F}_{4} \mathrm{~N}_{5} \mathrm{O}_{4}$, 546.1759 , found $546.1768[\mathrm{M}+\mathrm{H}]^{+}$.

3.1.7. N-(4-Fluorobenzyl)-2-(5-(1-(2-(methylamino)-2-oxoethyl)-1H-pyrazol-4-yl)-2', 5' dioxo-2,3-dihydrospiro[indene-1,3'-pyrrolidin]-1'-yl)- $N-((S)-1,1,1$-trifluoropropan-2yl)acetamide (A7)

Prepared using the same procedure as for A5, except using 2-(5-bromo-2' $5^{\prime}$-dioxo-2,3dihydrospiro[indene-1,3'-pyrrolidin]-1'-yl)- $N$-(4-fluorobenzyl)- $N$-((S)-1,1,1-trifluoropropan2-yl)acetamide $(\mathbf{8 2}, 0.10 \mathrm{~g}, 0.19 \mathrm{mmol})$ instead of $\mathbf{7 7}$ afforded $\mathbf{A 7}(0.02 \mathrm{~g}, 18 \%) .{ }^{1} \mathrm{H}-\mathrm{NMR}$ $\left(\mathrm{CDCl}_{3}\right) \delta 7.85(\mathrm{~s}, 1 \mathrm{H}), 7.67(\mathrm{~s}, 1 \mathrm{H}), 7.39(\mathrm{~s}, 1 \mathrm{H}), 7.37-7.33(\mathrm{~m}, 1 \mathrm{H}), 7.32-7.28(\mathrm{~m}, 2 \mathrm{H})$, $7.22(\mathrm{~d}, J=7.9 \mathrm{~Hz}, 1 \mathrm{H}), 7.10(\mathrm{t}, J=8.3 \mathrm{~Hz}, 2 \mathrm{H}), 6.26(\mathrm{~s}, 1 \mathrm{H}), 5.54-5.38(\mathrm{~m}, 1 \mathrm{H}), 4.83(\mathrm{~s}, 2 \mathrm{H})$, $4.74-4.61(\mathrm{~m}, 2 \mathrm{H}), 4.44-4.40(\mathrm{~m}, 1 \mathrm{H}), 4.18-4.12(\mathrm{~m}, 1 \mathrm{H}), 3.29-3.20(\mathrm{~m}, 1 \mathrm{H}), 3.09(\mathrm{~d}$, $J=6.5 \mathrm{~Hz}, 1 \mathrm{H}), 3.05(\mathrm{~d}, J=2.6 \mathrm{~Hz}, 1 \mathrm{H}), 3.01(\mathrm{~s}, 1 \mathrm{H}), 2.81(\mathrm{~d}, J=4.5 \mathrm{~Hz}, 3 \mathrm{H}), 2.26-2.17(\mathrm{~m}$, $1 \mathrm{H}), 1.66(\mathrm{~m}, 1 \mathrm{H}), 1.34-1.27(\mathrm{~m}, 3 \mathrm{H}) .{ }^{13} \mathrm{C}-\mathrm{NMR}\left(\mathrm{CDCl}_{3}\right) \delta 180.38,175.31,167.64,167.30$, $162.34(\mathrm{~d}, J=245 \mathrm{~Hz}), 144.97,138.88,132.04,128.04,127.31,127.23,125.16,125.11,123.68(\mathrm{q}$, $J=297 \mathrm{~Hz}), 123.27,123.08,122.19,122.12,116.39,116.17,55.47,55.24,46.10,43.44,40.68$, $38.02,31.35,29.72,26.28,11.57$. HPLC: retention time $11.664 \mathrm{~min}, 98.61 \%$ purity. HRMS (ESI): $m / z$ calcd for $\mathrm{C}_{30} \mathrm{H}_{29} \mathrm{~F}_{4} \mathrm{~N}_{5} \mathrm{O}_{4}, 600.2228$, found $600.2240[\mathrm{M}+\mathrm{H}]^{+}$.

3.1.8. N-(4-Fluorobenzyl)-2-(5-(3-methylureido)-2',5'-dioxo-2,3-dihydrospiro[indene-1,3'pyrrolidin]-1'-yl)-N-((S)-1,1,1-trifluoropropan-2-yl)acetamide (A8)

Prepared using the same procedure as for A2, except using 2-(5-amino-2', $5^{\prime}$-dioxo-2,3dihydrospiro[indene-1,3'-pyrrolidin]-1'-yl)- $N$-(4-fluorobenzyl)- $N$-((S)-1,1,1-trifluoro-propan-2yl)acetamide $(84,0.04 \mathrm{~g}, 0.09 \mathrm{mmol})$ instead of 79 afforded A8 $(0.03 \mathrm{~g}, 58 \%)$. ${ }^{1}$. H-NMR $\left(\mathrm{CDCl}_{3}\right) \delta 7.35-7.27(\mathrm{~m}, 2 \mathrm{H}), 7.14-6.99(\mathrm{~m}, 4 \mathrm{H}), 6.82(\mathrm{~d}, J=8.0 \mathrm{~Hz}, 1 \mathrm{H}), 5.41(\mathrm{dd}$, $J=12.9,6.6 \mathrm{~Hz}, 1 \mathrm{H}), 5.23(\mathrm{~d}, J=4.2 \mathrm{~Hz}, 1 \mathrm{H}), 4.74-4.60(\mathrm{~m}, 2 \mathrm{H}), 4.41-4.37(\mathrm{~m}, 1 \mathrm{H})$, $4.16-4.10(\mathrm{~m}, 1 \mathrm{H}), 3.09(\mathrm{~d}, J=8.3 \mathrm{~Hz}, 1 \mathrm{H}), 2.93(\mathrm{~s}, 2 \mathrm{H}), 2.74(\mathrm{~d}, J=4.0 \mathrm{~Hz}, 3 \mathrm{H}), 2.12(\mathrm{dd}$, 
$J=12.8,6.8 \mathrm{~Hz}, 1 \mathrm{H}), 1.77(\mathrm{~s}, 1 \mathrm{H}), 1.27(\mathrm{dd}, J=10.1,7.8 \mathrm{~Hz}, 3 \mathrm{H}) .{ }^{13} \mathrm{C}-\mathrm{NMR}\left(\mathrm{CDCl}_{3}\right) \delta 181.10$, $175.50,167.61,162.29$ (d, J = $245 \mathrm{~Hz}), 156.71,145.14,139.47,137.98,137.87,131.58,127.30$, $127.22,122.85,122.74,117.97$ (q, $J=269 \mathrm{~Hz}), 116.39,116.17,55.20,50.19,46.15,43.36,40.66$, 38.10, 31.39, 26.77, 11.49. HPLC: retention time $11.512 \mathrm{~min}, 93.15 \%$ purity. HRMS (ESI): $\mathrm{m} / \mathrm{z}$ calcd for $\mathrm{C}_{26} \mathrm{H}_{26} \mathrm{~F}_{4} \mathrm{~N}_{4} \mathrm{O}_{4}, 535.1963$, found $535.1975[\mathrm{M}+\mathrm{H}]^{+}$.

3.1.9. $N$-((2,2-Difluorobenzo[d][1,3]dioxol-5-yl)methyl)-2-((R)-5-(1-methyl-1H-pyrazol-4yl)-2', $4^{\prime}$-dioxo-2,3-dihydrospiro[indene-1, $5^{\prime}$-oxazolidin]-3'-yl)- $N-((S)-1,1,1-$ trifluoropropan-2-yl)acetamide (B1)

To a solution of 2-((S)-5-bromo-2' $4^{\prime}$-dioxo-2,3-dihydrospiro[indene-1,5'-oxazolidin]-3'yl)-N-((2,2-difluorobenzo[ $d][1,3]$ dioxol-5-yl)methyl)- $N-((S)-1,1,1$-trifluoropropan-2yl)acetamide (85, $0.26 \mathrm{~g}, 0.43 \mathrm{mmol}), 1$-methyl-4-(4,4,5,5-tetramethyl-1,3,2-dioxaborolan-2yl)- $1 H$-pyrazole $(0.099 \mathrm{~g}, 0.48 \mathrm{mmol})$ and $\mathrm{Pd}(\mathrm{dppf}) \mathrm{Cl}_{2}(0.031 \mathrm{~g}, 0.043 \mathrm{mmol})$ in 1,4-dioxane $(5 \mathrm{~mL})$ was added a saturated solution of sodium bicarbonate $(0.5 \mathrm{~mL})$ under nitrogen. The mixture was stirred in $85^{\circ} \mathrm{C}$ until completion, cooled to room temperature, concentrated, and purified directly by silica gel column chromatography to afford B1 $(0.068 \mathrm{~g}, 26 \%)$. ${ }^{1} \mathrm{H}-\mathrm{NMR}\left(\mathrm{CDCl}_{3}\right) \delta 7.75(\mathrm{~s}, 1 \mathrm{H}), 7.61(\mathrm{~s}, 1 \mathrm{H}), 7.51-7.43(\mathrm{~m}, 1 \mathrm{H}), 7.43-7.37(\mathrm{~m}, 2 \mathrm{H})$, $7.14-7.08(\mathrm{~m}, 1 \mathrm{H}), 7.06(\mathrm{~s}, 1 \mathrm{H}), 6.97-6.90(\mathrm{~m}, 1 \mathrm{H}), 5.63-5.40(\mathrm{~m}, 1 \mathrm{H}), 4.74-4.62(\mathrm{~m}$, $2 \mathrm{H}), 4.47-4.39(\mathrm{~m}, 1 \mathrm{H}), 4.26-4.20(\mathrm{~m}, 1 \mathrm{H}), 3.94(\mathrm{~s}, 3 \mathrm{H}), 3.31-3.20(\mathrm{~m}, 1 \mathrm{H}), 3.19-3.08$ $(\mathrm{m}, 1 \mathrm{H}), 2.85-2.74(\mathrm{~m}, 1 \mathrm{H}), 2.63-2.50(\mathrm{~m}, 1 \mathrm{H}), 1.32(\mathrm{~s}, 3 \mathrm{H}) .{ }^{13} \mathrm{C}-\mathrm{NMR}\left(\mathrm{CDCl}_{3}\right) \delta 174.26$, 174.10, 166.87, 154.37, 146.02, 144.60, 143.44, 136.96, 135.61, 134.90, 131.99, 131.67, 127.35, $125.29,124.85,123.72(\mathrm{q}, J=214 \mathrm{~Hz}), 121.84,120.66,110.18,107.13,94.82,50.61,46.21,41.66$, 39.18, 35.40, 30.27, 11.59. HPLC: retention time $13.762 \mathrm{~min}, 96.37 \%$ purity. HRMS (ESI): $\mathrm{m} / \mathrm{z}$ calcd for $\mathrm{C}_{28} \mathrm{H}_{23} \mathrm{~F}_{5} \mathrm{~N}_{4} \mathrm{O}_{6}, 607.1611$, found $607.1627[\mathrm{M}+\mathrm{H}]^{+}$.

3.1.10. N-(4-Fluorobenzyl)-2-((R)-5-(1-methyl-1H-pyrazol-4-yl)-2' '4'-dioxo-2,3dihydrospiro[indene-1,5'-oxazolidin]-3'-yl)- $N$-(8-methyl-8-azabicyclo[3.2.1]octan-3yl)acetamide (B2)

Prepared using the same procedure as for B1, except using 2-((R)-5-bromo-2' $4^{\prime}$ dioxo-2,3-dihydrospiro[indene-1,5'-oxazolidin]-3'-yl)-N-(4-fluorobenzyl)-N-(8-methyl-8azabicyclo[3.2.1] octan-3-yl)acetamide (86, $0.089 \mathrm{~g}, 0.16 \mathrm{mmol})$ instead of 85 to afford $\mathbf{B 2}$ $(0.015 \mathrm{~g}, 17 \%) .{ }^{1} \mathrm{H}-\mathrm{NMR}\left(\mathrm{CDCl}_{3}\right) \delta 7.79-7.72(\mathrm{~m}, 1 \mathrm{H}), 7.64-7.58(\mathrm{~m}, 1 \mathrm{H}), 7.54(\mathrm{~d}$, $J=7.9 \mathrm{~Hz}, 1 \mathrm{H}), 7.48-7.35(\mathrm{~m}, 3 \mathrm{H}), 7.15-7.07(\mathrm{~m}, 2 \mathrm{H}), 7.02-6.95(\mathrm{~m}, 1 \mathrm{H}), 4.67(\mathrm{~s}, 1 \mathrm{H})$, $4.54-4.40(\mathrm{~m}, 3 \mathrm{H}), 4.33(\mathrm{~s}, 1 \mathrm{H}), 4.01-3.87(\mathrm{~m}, 3 \mathrm{H}), 3.54(\mathrm{~s}, 1 \mathrm{H}), 3.31-3.24(\mathrm{~m}, 1 \mathrm{H})$, $3.19-3.13(\mathrm{~m}, 1 \mathrm{H}), 2.86-2.79(\mathrm{~m}, 1 \mathrm{H}), 2.64-2.51(\mathrm{~m}, 3 \mathrm{H}), 2.29-2.17(\mathrm{~m}, 3 \mathrm{H}), 2.01(\mathrm{~d}$, $J=5.2 \mathrm{~Hz}, 1 \mathrm{H}), 1.26(\mathrm{~s}, 4 \mathrm{H}), 0.88(\mathrm{~s}, 2 \mathrm{H})$. HPLC: retention time $13.183 \mathrm{~min}, 97.55 \%$ purity. HRMS (ESI): $m / z$ calcd for $\mathrm{C}_{32} \mathrm{H}_{34} \mathrm{FN}_{5} \mathrm{O}_{4}, 572.2668$, found $572.2687[\mathrm{M}+\mathrm{H}]^{+}$.

3.1.11. N-(4-Fluorobenzyl)-2-(5-(1-methyl-1H-pyrazol-4-yl)-2' ,4'-dioxo-2,3-dihydrospiro [indene-1, $5^{\prime}$-oxazolidin]-3'-yl)- $N-((S)$-quinuclidin-3-yl)acetamide (B3)

To a solution of 2-(5-(1-methyl-1H-pyrazol-4-yl)-2' $4^{\prime}$-dioxo-2,3-dihydrospiro[indene$1,5^{\prime}$-oxazolidin]-3'-yl)- $N-((S)$-quinuclidin-3-yl)acetamide $(0.12 \mathrm{~g}, 0.26 \mathrm{mmol})$ and 1(bromomethyl)-4-fluorobenzene $(0.14 \mathrm{~g}, 0.78 \mathrm{mmol})$ in DMF $(2 \mathrm{~mL})$ was added $\mathrm{K}_{2} \mathrm{CO}_{3}$ $(0.14 \mathrm{~g}, 1 \mathrm{mmol})$. The mixture was stirred at room temperature overnight. After completion, water $(10 \mathrm{~mL})$ was added. The mixture was extracted with ethyl acetate. The organic phase was combined, dried over anhydrous $\mathrm{Na}_{2} \mathrm{SO}_{4}$, and concentrated under vacuum. The residue was purified by silica gel column chromatography (MeOH:DCM $=10: 1)$ to afford B3 $(0.50 \mathrm{~g}, 34 \%) .{ }^{1} \mathrm{H}-\mathrm{NMR}\left(400 \mathrm{MHz}, \mathrm{CDCl}_{3}\right) \delta 8.82-8.62(\mathrm{~m}, 1 \mathrm{H}), 7.71(\mathrm{~s}, 1 \mathrm{H}), 7.60(\mathrm{~s}$, $1 \mathrm{H}), 7.44-7.38(\mathrm{~m}, 3 \mathrm{H}), 7.34(\mathrm{~d}, J=5.0 \mathrm{~Hz}, 1 \mathrm{H}), 7.08(\mathrm{~s}, 2 \mathrm{H}), 4.50-4.39(\mathrm{~m}, 4 \mathrm{H}), 3.91(\mathrm{~s}$, $3 \mathrm{H}), 3.28-3.18(\mathrm{~m}, 2 \mathrm{H}), 3.15-3.06(\mathrm{~m}, 2 \mathrm{H}), 2.95(\mathrm{~s}, 2 \mathrm{H}), 2.84-2.74(\mathrm{~m}, 2 \mathrm{H}), 2.62-2.29$ $(\mathrm{m}, 4 \mathrm{H}), 1.95-1.76(\mathrm{~m}, 4 \mathrm{H}) .{ }^{13} \mathrm{C}-\mathrm{NMR}\left(101 \mathrm{MHz}, \mathrm{CDCl}_{3}\right) \delta 174.43,166.10,162.36(\mathrm{~d}$, $J=245 \mathrm{~Hz}), 154.96,146.03,136.87,135.54,135.31,135.10,127.41,125.23,124.74,122.53$, $122.17,121.76,116.75,116.53,115.90,115.68,115.53,94.52,52.89,45.45,41.99,39.15,38.62$, 
$35.20,30.29,24.97,22.50,18.75$. HPLC: retention time $8.273 \mathrm{~min}, 95.59 \%$ purity. HRMS (ESI): $\mathrm{m} / z$ calcd for $\mathrm{C}_{31} \mathrm{H}_{32} \mathrm{FN}_{5} \mathrm{O}_{4}, 558.2511$, found $558.2522[\mathrm{M}+\mathrm{H}]^{+}$.

3.1.12. $N$-((S)-2,3-Dihydro-1H-inden-1-yl)-N-(4-fluorobenzyl)-2-(5-(1-methyl-1H-pyrazol4-yl)-2' ', ' $^{\prime}$-dioxo-2,3-dihydrospiro[indene-1,5'-oxazolidin]-3'-yl)acetamide (B4)

To a solution of 2-(5-bromo-2' , $^{\prime}$-dioxo-2,3-dihydrospiro[indene-1,5'-oxazolidin]-3' yl)- $N$-((S)-2,3-dihydro- $1 H$-inden-1-yl)- $N$-(4-fluorobenzyl)acetamide $(\mathbf{8 8}, 0.10 \mathrm{~g}, 0.18 \mathrm{mmol})$, 1-methyl-4-(4,4,5,5-tetramethyl-1,3,2-dioxaborolan-2-yl)-1H-pyrazole $(0.04 \mathrm{~g}, 0.20 \mathrm{mmol})$ and $\mathrm{Pd}(\mathrm{dppf}) \mathrm{Cl}_{2}(0.013 \mathrm{~g}, 0.018 \mathrm{mmol})$ in 1,4-dioxane $(5 \mathrm{~mL})$ was added a saturated solution of sodium bicarbonate $(0.5 \mathrm{~mL})$ under nitrogen. The mixture was stirred in $85{ }^{\circ} \mathrm{C}$ until completion. The mixture was cooled to room temperature, quenched with water $(10 \mathrm{~mL})$, and extracted with ethyl acetate. The organic phase was combined, dried over anhydrous $\mathrm{Na}_{2} \mathrm{SO}_{4}$, and concentrated under vacuum. The residue was purified by silica gel column chromatography (DCM: $\mathrm{MeOH}=20: 1)$ to afford $\mathbf{B} 4(0.080 \mathrm{~g}, 80 \%) .{ }^{1} \mathrm{H}-\mathrm{NMR}\left(\mathrm{CDCl}_{3}\right) \delta$ $7.75(\mathrm{~s}, 1 \mathrm{H}), 7.61(\mathrm{~s}, 1 \mathrm{H}), 7.58-7.51(\mathrm{~m}, 1 \mathrm{H}), 7.45-7.36(\mathrm{~m}, 2 \mathrm{H}), 7.29(\mathrm{~s}, 1 \mathrm{H}), 7.25-7.18$ $(\mathrm{m}, 4 \mathrm{H}), 7.10-6.99(\mathrm{~m}, 2 \mathrm{H}), 6.97-6.88(\mathrm{~m}, 1 \mathrm{H}), 5.61-5.30(\mathrm{~m}, 1 \mathrm{H}), 4.73-4.55(\mathrm{~m}$, $1 \mathrm{H}), 4.53-4.43(\mathrm{~m}, 1 \mathrm{H}), 4.28-4.17(\mathrm{~m}, 1 \mathrm{H}), 4.10-4.01(\mathrm{~m}, 1 \mathrm{H}), 3.94(\mathrm{~s}, 3 \mathrm{H}), 3.35-3.21$ $(\mathrm{m}, 1 \mathrm{H}), 3.22-3.08(\mathrm{~m}, 1 \mathrm{H}), 2.82(\mathrm{~d}, J=6.3 \mathrm{~Hz}, 2 \mathrm{H}), 2.62-2.57(\mathrm{~m}, 1 \mathrm{H}), 2.49-2.36(\mathrm{~m}$, $1 \mathrm{H}), 2.09-1.91(\mathrm{~m}, 1 \mathrm{H}), 1.91-1.69(\mathrm{~m}, 1 \mathrm{H}) .{ }^{13} \mathrm{C}-\mathrm{NMR}\left(\mathrm{CDCl}_{3}\right) \delta 174.45,166.11,162.20$ $(\mathrm{d}, J=245 \mathrm{~Hz}), 154.73,146.02,143.92,143.34,140.43,136.98,135.51,135.15,128.84,128.29$, $127.34,127.23,126.91,125.34,125.04,124.33,122.73,121.81,116.19,115.40,115.18,94.66$, 60.60, 46.20, 41.83, 39.19, 35.45, 31.14, 30.32, 30.14. HPLC: retention time $16.846 \mathrm{~min}, 98.62 \%$ purity.HRMS (ESI): $m / z$ calcd for $\mathrm{C}_{33} \mathrm{H}_{29} \mathrm{FN}_{4} \mathrm{O}_{4}, 565.2249$, found $565.2258[\mathrm{M}+\mathrm{H}]^{+}$.

3.1.13. $N-\left((S)-2,3-D i h y d r o-1 H\right.$-inden-1-yl)-N-(4-fluorobenzyl)-2-(5-(3-methylureido)-2' $4^{\prime}$ dioxo-2,3-dihydrospiro[indene-1,5'-oxazolidin]-3'-yl)acetamide (B5)

Prepared using with the same procedure as for A3, except using 2-(5-amino-2', $5^{\prime}$ dioxo-2,3-dihydrospiro[indene-1,3'-pyrrolidin]-1'-yl)- $N$-((S)-2,3-dihydro- $1 \mathrm{H}$-inden-1-yl)- $\mathrm{N}$ (4-fluorobenzyl)acetamide $(\mathbf{9 0}, 0.11 \mathrm{~g}, 0.22 \mathrm{mmol})$ instead of 79 afforded $\mathbf{B} 5(0.061 \mathrm{~g}, 50 \%)$. ${ }^{1} \mathrm{H}-\mathrm{NMR}\left(\mathrm{CDCl}_{3}\right) \delta 7.56-7.45(\mathrm{~m}, 1 \mathrm{H}), 7.33-7.28(\mathrm{~m}, 2 \mathrm{H}), 7.23-7.16(\mathrm{~m}, 3 \mathrm{H}), 7.12(\mathrm{~d}$, $J=7.3 \mathrm{~Hz}, 1 \mathrm{H}), 7.06(\mathrm{~d}, J=7.8 \mathrm{~Hz}, 1 \mathrm{H}), 6.99(\mathrm{~d}, J=3.7 \mathrm{~Hz}, 1 \mathrm{H}), 6.94-6.78(\mathrm{~m}, 2 \mathrm{H}), 5.42(\mathrm{t}$, $J=7.0 \mathrm{~Hz}, 1 \mathrm{H}), 5.25(\mathrm{~d}, J=5.2 \mathrm{~Hz}, 1 \mathrm{H}), 4.81(\mathrm{dd}, J=15.5,10.5 \mathrm{~Hz}, 1 \mathrm{H}), 4.71-4.56(\mathrm{~m}$, $1 \mathrm{H}), 4.54-4.41(\mathrm{~m}, 1 \mathrm{H}), 4.24(\mathrm{q}, J=11.6 \mathrm{~Hz}, 1 \mathrm{H}), 4.11-3.97(\mathrm{~m}, 1 \mathrm{H}), 3.17-3.06(\mathrm{~m}, 1 \mathrm{H})$, $3.06-2.95(\mathrm{~m}, 1 \mathrm{H}), 2.79(\mathrm{dd}, J=13.0,6.6 \mathrm{~Hz}, 2 \mathrm{H}), 2.72(\mathrm{~d}, J=3.3 \mathrm{~Hz}, 3 \mathrm{H}), 2.60-2.49(\mathrm{~m}$, $1 \mathrm{H}), 2.46-2.33(\mathrm{~m}, 1 \mathrm{H}), 2.08-1.92(\mathrm{~m}, 1 \mathrm{H}), 1.77-1.60(\mathrm{~m}, 1 \mathrm{H}) .{ }^{13} \mathrm{C}-\mathrm{NMR}\left(\mathrm{CDCl}_{3}\right) \delta$ 174.70, 166.38, 165.66, $162.22(\mathrm{~d}, J=246 \mathrm{~Hz}), 156.31,154.85,146.76,142.13,128.93,128.37$, $127.38,126.93,125.41,125.09,124.77,124.20,123.51,118.68,116.00,115.44,95.05,95.00,60.93$, 46.46, 41.83, 35.52, 31.94, 31.64, 30.37, 29.71, 26.74. HPLC: retention time $15.446 \mathrm{~min}, 99.17 \%$ purity. HRMS (ESI): $m / z$ calcd for $\mathrm{C}_{31} \mathrm{H}_{29} \mathrm{FN}_{4} \mathrm{O}_{5}, 557.2195$, found $557.2210[\mathrm{M}+\mathrm{H}]^{+}$.

3.1.14. N-((S)-2,3-Dihydro-1H-inden-1-yl)-N-(4-fluorobenzyl)-2-(5-(1-(2-hydroxy-2methylpropyl)-1H-pyrazol-4-yl)-2' '4'-dioxo-2,3-dihydrospiro[indene-1,5'-oxazolidin]-3'yl)acetamide (B6)

To a solution of 2-(5-bromo-2' , $^{\prime}$-dioxo-2,3-dihydrospiro[indene-1, $5^{\prime}$-oxazolidin]-3'yl)-N-((S)-2,3-dihydro-1H-inden-1-yl)- $N$-(4-fluorobenzyl) acetamide $(\mathbf{8 8}, 0.10 \mathrm{~g}, 0.18 \mathrm{mmol})$, 2-methyl-1-(4-(4,4,5,5-tetramethyl-1,3,2-dioxaborolan-2-yl)-1H-pyrazol-1-yl)propan-2-ol $(0.052 \mathrm{~g}, 0.20 \mathrm{mmol})$ and $\mathrm{Pd}(\mathrm{dppf}) \mathrm{Cl}_{2}(0.013 \mathrm{~g}, 0.018 \mathrm{mmol})$ in 1,4-dioxane $(5 \mathrm{~mL})$ was added a saturated solution of sodium bicarbonate $(0.5 \mathrm{~mL})$ under nitrogen. The mixture was stirred in $85^{\circ} \mathrm{C}$ until completion, quenched with water $(10 \mathrm{~mL})$, and extracted with ethyl acetate. The organic phase was combined, dried over anhydrous $\mathrm{Na}_{2} \mathrm{SO}_{4}$, and concentrated under vacuum. The residue was purified by silica gel column chromatography (DCM: $\mathrm{MeOH}=20: 1)$ to afford $\mathbf{B 6}(0.061 \mathrm{~g}, 55 \%) .{ }^{1} \mathrm{H}-\mathrm{NMR}\left(\mathrm{CDCl}_{3}\right) \delta 7.81(\mathrm{~s}, 1 \mathrm{H}), 7.68(\mathrm{~s}$, $1 \mathrm{H}), 7.55(\mathrm{t}, J=8.6 \mathrm{~Hz}, 1 \mathrm{H}), 7.46-7.39(\mathrm{~m}, 2 \mathrm{H}), 7.30(\mathrm{~d}, J=8.1 \mathrm{~Hz}, 1 \mathrm{H}), 7.24-7.17(\mathrm{~m}, 4 \mathrm{H})$, 
$7.08-7.02(\mathrm{~m}, 2 \mathrm{H}), 6.95-6.90(\mathrm{~m}, 1 \mathrm{H}), 5.40(\mathrm{t}, J=6.6 \mathrm{~Hz}, 1 \mathrm{H}), 4.87(\mathrm{dd}, J=15.5,9.4 \mathrm{~Hz}$, $1 \mathrm{H}), 4.72-4.55(\mathrm{~m}, 1 \mathrm{H}), 4.49(\mathrm{~d}, J=5.3 \mathrm{~Hz}, 1 \mathrm{H}), 4.25-4.20(\mathrm{~m}, 1 \mathrm{H}), 4.09(\mathrm{~s}, 2 \mathrm{H}), 3.70$ $(\mathrm{s}, 1 \mathrm{H}), 3.31-3.25(\mathrm{~m}, 1 \mathrm{H}), 3.18-3.13(\mathrm{~m}, 1 \mathrm{H}), 2.88-2.80(\mathrm{~m}, 3 \mathrm{H}), 2.66-2.58(\mathrm{~m}, 1 \mathrm{H})$, $2.44-2.36(\mathrm{~m}, 1 \mathrm{H}), 1.20(\mathrm{~s}, 6 \mathrm{H}) .{ }^{13} \mathrm{C}-\mathrm{NMR}\left(\mathrm{CDCl}_{3}\right) \delta 174.38,166.10,162.20(\mathrm{~d}, J=245 \mathrm{~Hz})$, 154.67, 146.04, 140.43, 137.43, 135.40, 135.17, 128.84, 128.26, 127.41, 127.33, 127.22, 126.94, $125.38,125.20,125.04,124.34,122.28,121.89,116.18,115.97,115.38,115.16,94.60,70.74,62.09$, $46.23,41.84,35.44,31.13,30.31,30.14,29.71,26.88$. HPLC: retention time $16.483 \mathrm{~min}, 99.46 \%$ purity. HRMS (ESI): $m / z$ calcd for $\mathrm{C}_{36} \mathrm{H}_{35} \mathrm{FN}_{4} \mathrm{O}_{5}, 623.2664$, found $623.2663[\mathrm{M}+\mathrm{H}]^{+}$.

3.1.15. N-((S)-2,3-Dihydro-1H-inden-1-yl)-N-(4-fluorobenzyl)-2-(5-(1-(2-(methylamino)-2oxoethyl)-1H-pyrazol-4-yl)-2' $4^{\prime}$-dioxo-2,3-dihydrospiro[indene-1,5' -oxazolidin]-3'yl)acetamide (B7)

Prepared using the same procedure as for B6, except using $N$-methyl-2-(4- $(4,4,5,5-$ tetramethyl-1,3,2-dioxaborolan-2-yl)-1H-pyrazol-1-yl) acetamide (0.072 g, $0.27 \mathrm{mmol})$ instead of 2-methyl-1-(4-(4,4,5,5-tetramethyl-1,3,2-dioxaborolan-2-yl)-1H-pyrazol-1-yl)propan2-ol afforded B7 (0.07 g, 43\%). ${ }^{1} \mathrm{H}-\mathrm{NMR}\left(\mathrm{CDCl}_{3}\right) \delta 7.88(\mathrm{~s}, 1 \mathrm{H}), 7.71(\mathrm{~s}, 1 \mathrm{H}), 7.61-7.55$ $(\mathrm{m}, 1 \mathrm{H}), 7.42(\mathrm{~d}, J=14.3 \mathrm{~Hz}, 3 \mathrm{H}), 7.22(\mathrm{~d}, J=7.5 \mathrm{~Hz}, 4 \mathrm{H}), 7.10-7.01(\mathrm{~m}, 2 \mathrm{H}), 6.93(\mathrm{~s}, 1 \mathrm{H})$, $4.91-4.87(\mathrm{~m}, 1 \mathrm{H}), 4.83(\mathrm{~s}, 2 \mathrm{H}), 4.72-4.56(\mathrm{~m}, 1 \mathrm{H}), 4.52-4.46(\mathrm{~m}, 1 \mathrm{H}), 4.29-4.18(\mathrm{~m}$, $1 \mathrm{H}), 4.13-4.02(\mathrm{~m}, 1 \mathrm{H}), 3.29(\mathrm{dd}, J=14.9,6.5 \mathrm{~Hz}, 1 \mathrm{H}), 3.17(\mathrm{dd}, J=11.2,7.6 \mathrm{~Hz}, 1 \mathrm{H})$, $2.97-2.82(\mathrm{~m}, 4 \mathrm{H}), 2.81(\mathrm{~d}, J=4.5 \mathrm{~Hz}, 3 \mathrm{H}), 2.62(\mathrm{dd}, J=9.3,4.6 \mathrm{~Hz}, 1 \mathrm{H}), 2.41(\mathrm{~d}, J=5.8 \mathrm{~Hz}$, 1H). ${ }^{13} \mathrm{C}-\mathrm{NMR}\left(\mathrm{CDCl}_{3}\right) \delta 174.34,167.49,166.10,162.23(\mathrm{~d}, J=250 \mathrm{~Hz}), 154.64,146.15,138.97$, $135.86,134.51,128.86,128.32,127.40,127.22,126.95,125.49,125.38,125.22,125.03,124.32$, 123.67, 122.03, 116.19, 115.98, 115.39, 115.19, 94.49, 62.74, 55.28, 46.23, 41.86, 35.44, 30.31, 30.14, 29.71, 26.27. HPLC: retention time $15.455 \mathrm{~min}, 99.43 \%$ purity. HRMS (ESI): $\mathrm{m} / z$ calcd for $\mathrm{C}_{35} \mathrm{H}_{32} \mathrm{FN}_{5} \mathrm{O}_{5}, 622.2460$, found $622.2476[\mathrm{M}+\mathrm{H}]^{+}$.

3.1.16. N-((S)-6,7-Dihydro-5H-cyclopenta[b]pyridin-7-yl)-N-(4-fluorobenzyl)-2-(5-(1-(2(methylamino)-2-oxoethyl)-1H-pyrazol-4-yl)-2', $4^{\prime}$-dioxo-2,3-dihydrospiro[indene-1,5'oxazolidin]-3'-yl)acetamide (B8)

Prepared using the same procedure as for B4, except using 2-(5-bromo-2' $4^{\prime}$-dioxo-2,3dihydrospiro[indene-1, $5^{\prime}$-oxazolidin]-3'-yl)- $N-((S)-6,7-d i h y d r o-5 H$-cyclopenta[b]pyridin-7yl)- $N$-(4-fluorobenzyl)acetamide $(\mathbf{9 1}, 0.078 \mathrm{~g}, 0.14 \mathrm{mmol})$ instead of 88 afforded $\mathbf{B 8}(0.02 \mathrm{~g}$, 23\%). ${ }^{1} \mathrm{H}-\mathrm{NMR}\left(\mathrm{CDCl}_{3}\right) \delta 8.47(\mathrm{~s}, 1 \mathrm{H}), 7.88(\mathrm{~s}, 1 \mathrm{H}), 7.71(\mathrm{~s}, 1 \mathrm{H}), 7.63-7.49(\mathrm{~m}, 2 \mathrm{H})$, $7.46-7.37(\mathrm{~m}, 2 \mathrm{H}), 7.22-6.97(\mathrm{~m}, 4 \mathrm{H}), 6.90(\mathrm{~d}, J=6.7 \mathrm{~Hz}, 1 \mathrm{H}), 5.00-4.78(\mathrm{~m}, 3 \mathrm{H})$, $4.70-4.52(\mathrm{~m}, 2 \mathrm{H}), 4.38-4.23(\mathrm{~m}, 1 \mathrm{H}), 4.13-4.03(\mathrm{~m}, 1 \mathrm{H}), 3.34-3.10(\mathrm{~m}, 2 \mathrm{H}), 3.18-3.14$ $(\mathrm{m}, 1 \mathrm{H}), 2.85-2.81(\mathrm{~m}, 6 \mathrm{H}), 2.65-2.57(\mathrm{~m}, 1 \mathrm{H}), 2.49-2.46(\mathrm{~m}, 1 \mathrm{H}), 2.10-2.06(\mathrm{~m}, 1 \mathrm{H})$. ${ }^{13} \mathrm{C}-\mathrm{NMR}\left(\mathrm{CDCl}_{3}\right) \delta 174.36,167.53,161.97(\mathrm{~d}, J=222 \mathrm{~Hz}), 149.13,148.46,146.13,139.01$, $135.95,134.42,133.20,133.06,132.27,128.72,128.32,127.83,125.46,125.24,123.72,123.32$, 122.02, 116.11, 115.90, 115.34, 115.13, 94.45, 61.18, 55.28, 47.56, 41.95, 35.33, 30.30, 28.76, 27.76, 26.28. HPLC: retention time $12.824 \mathrm{~min}, 99.49 \%$ purity. HRMS (ESI): $\mathrm{m} / z$ calcd for $\mathrm{C}_{34} \mathrm{H}_{31} \mathrm{FN}_{6} \mathrm{O}_{5}, 623.2413$, found 623.2424 [M + H] ${ }^{+}$.

3.1.17. $N-((S)-5-F l u o r o-2,3-d i h y d r o-1 H$-inden-1-yl)-N-(4-fluorobenzyl)-2-(5-(1-(2(methylamino)-2-oxoethyl)-1H-pyrazol-4-yl)-2' , $4^{\prime}$-dioxo-2,3-dihydrospiro[indene-1,5'oxazolidin]-3'-yl)acetamide (B9)

Prepared using the same procedure as for B4, except using 2-(5-bromo-2 ${ }^{\prime} 4^{\prime}$-dioxo-2,3dihydrospiro[indene-1,5'-oxazolidin]-3'-yl)-N-(5-fluoro-2,3-dihydro-1H-inden-1-yl)-N-(4fluorobenzyl) acetamide $(\mathbf{9 3}, 0.22 \mathrm{~g}, 0.38 \mathrm{mmol})$ instead of $\mathbf{8 8}$ afforded $\mathbf{B 9}(0.08 \mathrm{~g}, 33.3 \%)$. ${ }^{1} \mathrm{H}-\mathrm{NMR}\left(\mathrm{CDCl}_{3}\right) \delta 7.88(\mathrm{~s}, 1 \mathrm{H}), 7.71(\mathrm{~s}, 1 \mathrm{H}), 7.61-7.52(\mathrm{~m}, 1 \mathrm{H}), 7.43(\mathrm{t}, J=10.5 \mathrm{~Hz}, 2 \mathrm{H})$, $7.18(\mathrm{~d}, J=4.9 \mathrm{~Hz}, 1 \mathrm{H}), 7.16-6.99(\mathrm{~m}, 3 \mathrm{H}), 6.92(\mathrm{dd}, J=12.5,7.9 \mathrm{~Hz}, 3 \mathrm{H}), 4.91-4.76$ $(\mathrm{m}, 3 \mathrm{H}), 4.65-4.60(\mathrm{~m}, 1 \mathrm{H}), 4.51-4.44(\mathrm{~m}, 1 \mathrm{H}), 4.27-4.20(\mathrm{~m}, 1 \mathrm{H}), 4.12-4.03(\mathrm{~m}$, $1 \mathrm{H}), 3.40-3.07(\mathrm{~m}, 2 \mathrm{H}), 2.92-2.76(\mathrm{~m}, 6 \mathrm{H}), 2.67-2.56(\mathrm{~m}, 1 \mathrm{H}), 2.47-2.42(\mathrm{~m}, 1 \mathrm{H})$, $1.92-1.83(\mathrm{~m}, 1 \mathrm{H}) .{ }^{13} \mathrm{C}-\mathrm{NMR}\left(101 \mathrm{MHz}, \mathrm{CDCl}_{3}\right) \delta 174.36,167.90,167.50,166.08,163.59$ (d, $J=325 \mathrm{~Hz}), 162.24(\mathrm{~d}, J=245 \mathrm{~Hz}), 154.62,146.16,141.41,138.97,135.80,134.54,132.23$, 
$131.18,128.76,128.34,127.40,125.49,125.19,123.64,122.04,116.26,114.29,111.87,106.75$, $94.54,61.90,59.88,55.28,46.18,41.83,35.40,31.49,30.32,26.29$. HPLC: retention time $13.277 \mathrm{~min}, 98.78 \%$ purity. HRMS (ESI): $\mathrm{m} / \mathrm{z}$ calcd for $\mathrm{C}_{35} \mathrm{H}_{31} \mathrm{~F}_{2} \mathrm{~N}_{5} \mathrm{O}_{5}, 640.2366$, found $640.2375[\mathrm{M}+\mathrm{H}]^{+}$.

3.1.18. $N-((R)-2,3-D i h y d r o-1 H$-inden-1-yl)-N-(4-fluorobenzyl)-2-(5-(1-(2-(methylamino)-2oxoethyl)-1H-pyrazol-4-yl)-2' $4^{\prime}$-dioxo-2,3-dihydrospiro[indene-1,5'-oxazolidin]-3'yl)acetamide (B10)

Prepared using the same procedure as for B4, except using 2-(5-bromo-2' $4^{\prime}$-dioxo2,3-dihydrospiro[indene-1,5'-oxazolidin]-3'-yl)- $N-((R)-2,3$-dihydro- $1 H$-inden-1-yl)-N-(4fluorobenzyl)acetamide $(92,0.10 \mathrm{~g}, 0.18 \mathrm{mmol})$ instead of 88 afforded $\mathbf{B 1 0}(0.02 \mathrm{~g}, 18 \%)$. ${ }^{1} \mathrm{H}-\mathrm{NMR}\left(\mathrm{CDCl}_{3}\right) \delta 7.89(\mathrm{~s}, 1 \mathrm{H}), 7.72(\mathrm{~s}, 1 \mathrm{H}), 7.61-7.54(\mathrm{~m}, 1 \mathrm{H}), 7.44(\mathrm{t}, J=11.1 \mathrm{~Hz}, 3 \mathrm{H})$, $7.25-7.16(\mathrm{~m}, 4 \mathrm{H}), 7.10-7.00(\mathrm{~m}, 2 \mathrm{H}), 6.96-6.89(\mathrm{~m}, 1 \mathrm{H}), 4.84(\mathrm{~s}, 2 \mathrm{H}), 4.69-4.57(\mathrm{~m}$, $1 \mathrm{H}), 4.54-4.44(\mathrm{~m}, 1 \mathrm{H}), 4.37-4.15(\mathrm{~m}, 2 \mathrm{H}), 4.15-3.93(\mathrm{~m}, 1 \mathrm{H}), 3.32-3.26(\mathrm{~m}, 1 \mathrm{H})$, $3.20-3.14(\mathrm{~m}, 1 \mathrm{H}), 2.84(\mathrm{~s}, 2 \mathrm{H}), 2.81(\mathrm{~d}, J=3.5 \mathrm{~Hz}, 3 \mathrm{H}), 2.80-2.69(\mathrm{~m}, 2 \mathrm{H}), 2.65-2.57(\mathrm{~m}$, $1 \mathrm{H}), 2.41(\mathrm{dd}, J=12.2,5.3 \mathrm{~Hz}, 1 \mathrm{H}) .{ }^{13} \mathrm{C}-\mathrm{NMR}\left(\mathrm{CDCl}_{3}\right) \delta 174.37,167.52,166.73,166.11,162.20$ $(\mathrm{d}, J=245 \mathrm{~Hz}), 146.15,141.42,139.00,135.85,134.50,130.96,128.86,128.34,127.32,125.50$, $125.39,124.30,123.66,122.03,120.53,116.21,115.99,115.21,106.77,99.99,94.51,60.61,55.27$, 50.92, 41.86, 35.36, 31.12, 30.32, 29.73, 26.30. HPLC: retention time $13.234 \mathrm{~min}, 99.56 \%$ purity (using XBridge C18 $\left(4.6^{*} 150 \mathrm{~mm}, 3.5 \mu \mathrm{m}\right)$ instead of Xselect CSH C18 $\left(4.6^{*} 150 \mathrm{~mm}, 3.5 \mu \mathrm{m}\right)$, and ammonia instead of trifluoroacetic acid). HRMS (ESI): $m / z$ calcd for $\mathrm{C}_{35} \mathrm{H}_{32} \mathrm{FN}_{5} \mathrm{O}_{5}$, 622.2460, found 622.2477 [M+ H] $]^{+}$.

3.1.19. $N-((R)-6,7-D i h y d r o-5 H-c y c l o p e n t a[b] p y r i d i n-5-y l)-N-(4-f l u o r o b e n z y l)-2-(5-(1-(2-$ (methylamino)-2-oxoethyl)-1H-pyrazol-4-yl)-2', $4^{\prime}$-dioxo-2,3-dihydrospiro[indene-1,5'oxazolidin]-3'-yl)acetamide (B11)

Prepared using the same procedure as for B4, except using 2-(5-bromo-2', $4^{\prime}$-dioxo2,3-dihydrospiro[indene-1,5'-oxazolidin]-3'-yl)- $N-((R)-2,3$-dihydro- $1 H$-inden-1-yl)- $N-((5-$ fluoropyridin-2-yl)methyl)acetamide $(94,0.089 \mathrm{~g}, 0.16 \mathrm{mmol})$ instead of 88 afforded B11 $(0.026 \mathrm{~g}, 26 \%) .{ }^{1} \mathrm{H}-\mathrm{NMR}\left(\mathrm{CDCl}_{3}\right) \delta 7.89(\mathrm{~s}, 1 \mathrm{H}), 7.71(\mathrm{~s}, 1 \mathrm{H}), 7.60-7.51(\mathrm{~m}, 2 \mathrm{H}), 7.48-7.42$ $(\mathrm{m}, 2 \mathrm{H}), 7.23-7.16(\mathrm{~m}, 2 \mathrm{H}), 7.11-7.05(\mathrm{~m}, 2 \mathrm{H}), 6.99(\mathrm{~s}, 1 \mathrm{H}), 6.96-6.90(\mathrm{~m}, 1 \mathrm{H}), 5.35(\mathrm{~s}$, $1 \mathrm{H}), 4.84(\mathrm{~s}, 2 \mathrm{H}), 4.48(\mathrm{t}, 2 \mathrm{H}), 4.30-4.26(\mathrm{~m}, 2 \mathrm{H}), 3.27(\mathrm{~s}, 1 \mathrm{H}), 3.18(\mathrm{~s}, 1 \mathrm{H}), 2.98(\mathrm{~s}, 2 \mathrm{H}), 2.81$ $(\mathrm{d}, 3 \mathrm{H}), 2.61(\mathrm{~s}, 2 \mathrm{H}), 2.49(\mathrm{~s}, 2 \mathrm{H})$. HPLC: retention time $8.859 \mathrm{~min}, 96.88 \%$ purity. HRMS (ESI): $m / z$ calcd for $\mathrm{C}_{34} \mathrm{H}_{31} \mathrm{FN}_{6} \mathrm{O}_{5}, 623.2413$, found $623.2425[\mathrm{M}+\mathrm{H}]^{+}$.

3.1.20. $N-((R)-2,3-D i h y d r o-1 H$-inden-1-yl)-N-((5-fluoropyridin-2-yl)methyl)-2-(5-(1-(2(methylamino)-2-oxoethyl)-1H-pyrazol-4-yl)-2' , 4'-dioxo-2,3-dihydrospiro[indene-1,5'oxazolidin]-3'-yl)acetamide (B12)

Prepared using the same procedure as for B4, except using 2-(5-bromo-2 ${ }^{\prime} 4^{\prime}$-dioxo-2,3dihydrospiro[indene-1,5'-oxazolidin]-3'-yl)- $N-((R)-2,3$-dihydro- $1 H$-inden-1-yl)- $N$-((5-fluoropyridin-2-yl)methyl)acetamide $(\mathbf{9 5}, 0.11 \mathrm{~g}, 0.20 \mathrm{mmol})$ instead of 88 afforded B12 (0.05 g, 39\%). ${ }^{1} \mathrm{H}-\mathrm{NMR}\left(\mathrm{CDCl}_{3}\right) \delta 8.42(\mathrm{~s}, 1 \mathrm{H}), 8.27(\mathrm{~s}, 1 \mathrm{H}), 7.88(\mathrm{~s}, 1 \mathrm{H}), 7.71(\mathrm{~s}, 1 \mathrm{H}), 7.66-7.49$ $(\mathrm{m}, 2 \mathrm{H}), 7.44(\mathrm{t}, J=8.0 \mathrm{~Hz}, 2 \mathrm{H}), 7.33(\mathrm{~d}, J=7.8 \mathrm{~Hz}, 1 \mathrm{H}), 7.21(\mathrm{~s}, 2 \mathrm{H}), 7.16-7.02(\mathrm{~m}$, $2 \mathrm{H}), 4.95-4.79(\mathrm{~m}, 3 \mathrm{H}), 4.73-4.63(\mathrm{~m}, 1 \mathrm{H}), 4.53-4.46(\mathrm{~m}, 1 \mathrm{H}), 4.39-4.33(\mathrm{~m}, 1 \mathrm{H})$, $4.27-4.18(\mathrm{~m}, 1 \mathrm{H}), 3.38-3.10(\mathrm{~m}, 2 \mathrm{H}), 3.02-2.97(\mathrm{~m}, 1 \mathrm{H}), 2.92-2.76(\mathrm{~m}, 6 \mathrm{H}), 2.62(\mathrm{~d}$, $J=5.1 \mathrm{~Hz}, 1 \mathrm{H}), 2.49-2.36(\mathrm{~m}, 1 \mathrm{H}) .{ }^{13} \mathrm{C}-\mathrm{NMR}\left(\mathrm{CDCl}_{3}\right) \delta 174.36,167.50,166.28,158.69(\mathrm{~d}$, $J=255 \mathrm{~Hz}), 154.63,153.63,146.13,144.03,141.38,140.24,138.95,137.97,135.96,134.47$, $128.82,128.32,127.22,125.49,124.98,124.83,123.70,122.03,121.75,94.56,94.42,60.47,55.28$, $47.95,41.93,35.41,30.50,30.31,29.70,26.27$. HPLC: retention time $11.706 \mathrm{~min}, 94.84 \%$ purity. HRMS (ESI): $m / z$ calcd for $\mathrm{C}_{34} \mathrm{H}_{31} \mathrm{FN}_{6} \mathrm{O}_{5}, 623.2413$, found $623.2435[\mathrm{M}+\mathrm{H}]^{+}$. 
3.1.21. $N-((R)-6,7-D i h y d r o-5 H-c y c l o p e n t a[b] p y r i d i n-7-y l)-N-((5-f l u o r o p y r i d i n-2-y l)$ methyl)-2-(5-(1-(2-(methylamino)-2-oxoethyl)-1H-pyrazol-4-yl)-2', $4^{\prime}$-dioxo-2,3dihydrospiro[indene-1, $5^{\prime}$-oxazolidin]-3'-yl)acetamide (B13)

Prepared using the same procedure as for B4, except using 2-(5-bromo-2' $4^{\prime}$-dioxo-2,3dihydrospiro [indene-1, $5^{\prime}$-oxazolidin]-3'-yl)- $N-((R)-6,7-d i h y d r o-5 H$-cyclopenta[b]pyridin-7yl)- $N$-((5-fluoropyridin-2-yl)methyl)acetamide $(\mathbf{9 6}, 0.20 \mathrm{~g}, 0.36 \mathrm{mmol})$ instead of $\mathbf{8 8}$ afforded B13 $(0.093 \mathrm{~g}, 41 \%) .{ }^{1} \mathrm{H}-\mathrm{NMR}\left(\mathrm{CDCl}_{3}\right) \delta 8.41(\mathrm{~s}, 1 \mathrm{H}), 8.20(\mathrm{~s}, 1 \mathrm{H}), 7.87(\mathrm{~s}, 1 \mathrm{H}), 7.71(\mathrm{~s}, 1 \mathrm{H})$, $7.62-7.49(\mathrm{~m}, 3 \mathrm{H}), 7.41(\mathrm{~d}, J=7.1 \mathrm{~Hz}, 2 \mathrm{H}), 7.30(\mathrm{~d}, J=5.3 \mathrm{~Hz}, 1 \mathrm{H}), 7.16-7.09(\mathrm{~m}, 1 \mathrm{H})$, $5.10-4.97(\mathrm{~m}, 1 \mathrm{H}), 4.82(\mathrm{~s}, 2 \mathrm{H}), 4.71-4.57(\mathrm{~m}, 2 \mathrm{H}), 4.51-4.39(\mathrm{~m}, 1 \mathrm{H}), 4.36-4.22(\mathrm{~m}$, $1 \mathrm{H}), 3.35-3.21(\mathrm{~m}, 1 \mathrm{H}), 3.17(\mathrm{~s}, 1 \mathrm{H}), 3.09-2.97(\mathrm{~m}, 1 \mathrm{H}), 2.95-2.75(\mathrm{~m}, 6 \mathrm{H}), 2.66-2.57$ $(\mathrm{m}, 1 \mathrm{H}), 2.56-2.47(\mathrm{~m}, 1 \mathrm{H}) .{ }^{13} \mathrm{C}-\mathrm{NMR}\left(\mathrm{CDCl}_{3}\right) \delta 167.51,165.90,160.60,159.74,154.62$, $153.63(\mathrm{~d}, J=226 \mathrm{~Hz}), 149.05,148.50,146.10,138.96,138.13,137.89,136.49,135.97,134.45$, $133.16,131.25,128.31,125.44,123.69,123.26,122.71,122.00,94.50,62.15,55.27,49.23,41.86$, $35.40,30.30,28.27,27.82,26.27$. HPLC: retention time $8.882 \mathrm{~min}, 95.24 \%$ purity. HRMS (ESI): $m / z$ calcd for $\mathrm{C}_{33} \mathrm{H}_{30} \mathrm{FN}_{7} \mathrm{O}_{5}, 624.2365$, found $624.2375[\mathrm{M}+\mathrm{H}]^{+}$.

3.1.22. $N$-(4-Fluorobenzyl)- $N$-((S)-1-methyl-4,5,6,7-tetrahydro-1H-indazol-4-yl)-2-(5-(1-(2(methylamino)-2-oxoethyl)-1H-pyrazol-4-yl)-2', ,'-dioxo-2,3-dihydrospiro [indene-1,5'-oxazolidin]-3'-yl)acetamide (B14)

Prepared using the same procedure as for B4, except using 2-(5-bromo-2' ${ }^{\prime} 4^{\prime}$-dioxo-2,3dihydrospiro[indene-1,5'-oxazolidin]-3'-yl)- $N$-(4-fluorobenzyl)- $N$-((S)-1-methyl-4,5,6,7tetrahydro- $1 \mathrm{H}$-indazol-4-yl) acetamide $(\mathbf{9 7}, 0.15 \mathrm{~g}, 0.27 \mathrm{mmol})$ instead of $\mathbf{8 8}$ afforded B14 $(0.059 \mathrm{~g}, 35 \%) .{ }^{1} \mathrm{H}-\mathrm{NMR}\left(\mathrm{CDCl}_{3}\right) \delta 7.89(\mathrm{~s}, 1 \mathrm{H}), 7.71(\mathrm{~s}, 1 \mathrm{H}), 7.57(\mathrm{dd}, J=14.2,6.2 \mathrm{~Hz}$, $1 \mathrm{H}), 7.44(\mathrm{~s}, 2 \mathrm{H}), 7.18-7.13(\mathrm{~m}, 1 \mathrm{H}), 7.06(\mathrm{t}, J=7.5 \mathrm{~Hz}, 2 \mathrm{H}), 6.93(\mathrm{~d}, J=5.6 \mathrm{~Hz}, 2 \mathrm{H})$, $4.83(\mathrm{~s}, 2 \mathrm{H}), 4.79-4.62(\mathrm{~m}, 1 \mathrm{H}), 4.49(\mathrm{~m}, 1 \mathrm{H}), 4.44-4.34(\mathrm{~m}, 2 \mathrm{H}), 4.27-4.10(\mathrm{~m}, 1 \mathrm{H})$, $3.28(\mathrm{dt}, J=14.7,7.4 \mathrm{~Hz}, 1 \mathrm{H}), 3.23-3.12(\mathrm{~m}, 1 \mathrm{H}), 3.11-2.95(\mathrm{~m}, 1 \mathrm{H}), 2.89(\mathrm{dd}, J=14.4$, $7.4 \mathrm{~Hz}, 1 \mathrm{H}), 2.82(\mathrm{~d}, J=4.5 \mathrm{~Hz}, 3 \mathrm{H}), 2.73-2.55(\mathrm{~m}, 2 \mathrm{H}), 2.55-2.44(\mathrm{~m}, 1 \mathrm{H}), 2.41-2.08$ (m, 3H). ${ }^{13} \mathrm{C}-\mathrm{NMR}\left(\mathrm{CDCl}_{3}\right) \delta 174.59,167.48,165.11,153.24(\mathrm{~d}, J=278 \mathrm{~Hz}), 151.85,146.15$, $138.98,135.82$, 134.52, 133.90, 133.99, 133.87, 132.32, 129.09, 128.31, 127.68, 127.59, 125.50, $123.67,122.02$, 116.12, 115.90, 94.51, 55.20, 54.04, 46.30, 41.97, 39.50, 36.93, 35.52, 35.40, 30.31, 26.27, 21.70. HPLC: retention time $10.549 \mathrm{~min}, 97.97 \%$ purity. HRMS (ESI): $\mathrm{m} / \mathrm{z}$ calcd for $\mathrm{C}_{34} \mathrm{H}_{34} \mathrm{FN}_{7} \mathrm{O}_{5}, 626.2522$, found $626.2541[\mathrm{M}+\mathrm{H}]^{+}$.

3.1.23. $N$-(4-fluorobenzyl)-2-(5-(1-(2-(methylamino)-2-oxoethyl)-1H-pyrazol-4-yl)-2' $4^{\prime}$ dioxo-2,3-dihydrospiro[indene-1, $5^{\prime}$-oxazolidin]-3'-yl)- $N-((S)-1,2,3,4-$ tetrahydronaphthalen-1-yl)acetamide (B15)

To a solution of 2-(5-bromo-2', $4^{\prime}$-dioxo-2,3-dihydrospiro[indene-1,5'-oxazolidin]-3'-yl)- $N$ (4-fluorobenzyl)- $\mathrm{N}-((S)-1,2,3,4$-tetrahydronaphthalen-1-yl)acetamide $(98,0.15 \mathrm{~g}, 0.26 \mathrm{mmol})$, $\mathrm{N}$-methyl-2-(4-(4,4,5,5-tetramethyl-1,3,2-dioxaborolan-2-yl)-1H-pyrazol-1-yl) acetamide $(0.06 \mathrm{~g}, 0.29 \mathrm{mmol})$ and $\mathrm{Pd}(\mathrm{dppf}) \mathrm{Cl}_{2}(0.02 \mathrm{~g}, 0.026 \mathrm{mmol})$ in 1,4-dioxane $(5 \mathrm{~mL})$ was added a saturated solution of sodium bicarbonate $(0.5 \mathrm{~mL})$ under nitrogen. The mixture was stirred in $85^{\circ} \mathrm{C}$ until completion, quenched with water $(10 \mathrm{~mL})$, and extracted with ethyl acetate. The organic phase was combined, dried over anhydrous $\mathrm{Na}_{2} \mathrm{SO}_{4}$, and concentrated under vacuum. The residue was purified by silica gel column chromatography (EA:PE $=1: 1)$ to afford B15 $(0.09 \mathrm{~g}, 56 \%) .{ }^{1} \mathrm{H}-\mathrm{NMR}\left(\mathrm{DMSO}^{-} d_{6}\right) \delta 8.20(\mathrm{~s}, 1 \mathrm{H}), 8.03(\mathrm{~s}, 1 \mathrm{H}), 7.94(\mathrm{~s}$, $1 \mathrm{H}), 7.63(\mathrm{~s}, 1 \mathrm{H}), 7.55-7.48(\mathrm{~m}, 2 \mathrm{H}), 7.38(\mathrm{~s}, 1 \mathrm{H}), 7.20(\mathrm{~d}, \mathrm{~J}=12.3 \mathrm{~Hz}, 4 \mathrm{H}), 7.13-7.08$ $(\mathrm{m}, 2 \mathrm{H}), 4.92-4.55(\mathrm{~m}, 5 \mathrm{H}), 4.40-3.67(\mathrm{~m}, 2 \mathrm{H}), 3.26-3.05(\mathrm{~m}, 2 \mathrm{H}), 2.76-2.69(\mathrm{~m}, 2 \mathrm{H})$, $2.63(\mathrm{~d}, J=3.8 \mathrm{~Hz}, 3 \mathrm{H}), 2.59-2.53(\mathrm{~m}, 1 \mathrm{H}), 2.13-1.58(\mathrm{~m}, 5 \mathrm{H}) .{ }^{13} \mathrm{C}-\mathrm{NMR}\left(\mathrm{DMSO}^{-} \mathrm{d}_{6}\right) \delta$ $174.26,167.32,166.81,161.76(\mathrm{~d}, \mathrm{~J}=242 \mathrm{~Hz}), 154.74,146.61,138.93,137.45,135.71,135.63$, $135.22,134.34,129.96,129.63,129.12,128.55,127.79,127.41,126.74,126.56,125.03,121.89$, $121.78,116.04,115.19,94.27,56.93,54.74,46.86,42.03,35.16,30.26,29.48,29.08,26.09,22.03$. HPLC: retention time $15.903 \mathrm{~min}, 97.92 \%$ purity. HRMS (ESI): $m / z$ calcd for $\mathrm{C}_{36} \mathrm{H}_{34} \mathrm{FN}_{5} \mathrm{O}_{5}$, 636.2617, found 636.2621 [M+ H] $]^{+}$. 
3.1.24. $N$-((S)-chroman-4-yl)-N-(4-fluorobenzyl)-2-(5-(1-(2-(methylamino)-2-oxoethyl)1H-pyrazol-4-yl)-2' , $4^{\prime}$-dioxo-2,3-dihydrospiro[indene-1,5'-oxazolidin]-3' yl)acetamide (B16)

Prepared using the same procedure as for B15, except using 2-(5-bromo-2' $4^{\prime}$-dioxo2,3-dihydrospiro[indene-1,5' -oxazolidin]-3'-yl)- $N$-((S)-chroman-4-yl)-N-(4-fluorobenzyl) acetamide $(99,0.30 \mathrm{~g}, 0.52 \mathrm{mmol})$ instead of 98 afforded B16 $(0.11 \mathrm{~g}, 33 \%)$. ${ }^{1} \mathrm{H}-\mathrm{NMR}$ $\left(\mathrm{CDCl}_{3}\right) \delta 7.85(\mathrm{~s}, 1 \mathrm{H}), 7.71(\mathrm{~s}, 1 \mathrm{H}), 7.58-7.50(\mathrm{~m}, 1 \mathrm{H}), 7.40(\mathrm{~d}, J=13.2 \mathrm{~Hz}, 2 \mathrm{H}), 7.22(\mathrm{~s}$, $1 \mathrm{H}), 7.19-7.10(\mathrm{~m}, 2 \mathrm{H}), 7.10-7.02(\mathrm{~m}, 2 \mathrm{H}), 6.97-6.87(\mathrm{~m}, 2 \mathrm{H}), 6.79(\mathrm{~s}, 1 \mathrm{H}), 5.15-4.81$ $(\mathrm{m}, 1 \mathrm{H}), 4.81(\mathrm{~s}, 2 \mathrm{H}), 4.59-4.45(\mathrm{~m}, 2 \mathrm{H}), 4.28-4.05(\mathrm{~m}, 4 \mathrm{H}), 3.32-3.20(\mathrm{~m}, 1 \mathrm{H}), 3.14(\mathrm{dd}$, $J=11.8,8.0 \mathrm{~Hz}, 1 \mathrm{H}), 2.83(\mathrm{~d}, J=7.8 \mathrm{~Hz}, 1 \mathrm{H}), 2.78(\mathrm{~d}, J=4.1 \mathrm{~Hz}, 3 \mathrm{H}), 2.63-2.53(\mathrm{~m}, 1 \mathrm{H}), 2.06$ $(\mathrm{s}, 1 \mathrm{H}), 1.98(\mathrm{~d}, J=10.1 \mathrm{~Hz}, 1 \mathrm{H}) .{ }^{13} \mathrm{C}-\mathrm{NMR}\left(\mathrm{CDCl}_{3}\right) \delta 174.32,167.51,166.83,166.80,162.98$ $(\mathrm{d}, J=245 \mathrm{~Hz}), 156.45,154.59,146.14,138.82,135.73,134.62,129.27,128.40,127.71,127.35$, $125.44,125.09,123.52,122.04,121.24,121.17,120.10,117.34,116.32,116.10,94.60,64.92,55.22$, $50.36,46.66,41.76,35.31,30.29,27.17,26.27$. HPLC: retention time $12.527 \mathrm{~min}, 99.97 \%$ purity. HRMS (ESI): $m / z$ calcd for $\mathrm{C}_{35} \mathrm{H}_{32} \mathrm{FN}_{5} \mathrm{O}_{6}, 638.2409$, found $638.2415[\mathrm{M}+\mathrm{H}]^{+}$.

3.1.25. 1-(3'-(2-(7-(Difluoromethyl)-3,4-dihydroquinolin-1(2H)-yl)-2-oxoethyl)-2' , $4^{\prime}$-dioxo2,3-dihydrospiro[indene-1,5'-oxazolidin]-5-yl)-3-methylurea (B17)

To a solution of 5-amino-3'-(2-(7-(difluoromethyl)-3,4-dihydroquinolin-1(2H)-yl)-2oxoethyl)-2,3-dihydrospiro[indene-1,5' -oxazolidine]-2' $4^{\prime}$-dione (100, $\left.0.12 \mathrm{~g}, 0.27 \mathrm{mmol}\right)$ and triethylamine $(0.08 \mathrm{~g}, 0.816 \mathrm{mmol})$ in anhydrous tetrahydrofuran $(2 \mathrm{~mL})$ was added triphosgene $(0.08 \mathrm{~g}, 0.27 \mathrm{mmol})$. The mixture was stirred at room temperature for $30 \mathrm{~min}$. Then methylamine in tetrahydrofuran $(2.0 \mathrm{M}, 0.41 \mathrm{~mL})$ was added. The mixture was stirred for $1 \mathrm{~h}$, quenched with a saturated solution of sodium bicarbonate $(10 \mathrm{~mL})$ and extracted with ethyl acetate. The organic phase was combined, dried over anhydrous $\mathrm{Na}_{2} \mathrm{SO}_{4}$, and concentrated under vacuum. The residue was purified by silica gel column chromatography (EA:PE = 1:1) to afford B17 $(0.03 \mathrm{~g}, 22 \%) .{ }^{1} \mathrm{H}-\mathrm{NMR}\left(\mathrm{DMSO}-\mathrm{d}_{6}\right) \delta 7.97$ (s, $1 \mathrm{H}), 7.55(\mathrm{~s}, 1 \mathrm{H}), 7.39-7.21(\mathrm{~m}, 4 \mathrm{H}), 6.13(\mathrm{~d}, J=4.2 \mathrm{~Hz}, 1 \mathrm{H}), 4.69(\mathrm{~s}, 2 \mathrm{H}), 3.89-3.77(\mathrm{~m}$, 2H), $3.35(\mathrm{~s}, 1 \mathrm{H}), 3.18-3.07(\mathrm{~m}, 2 \mathrm{H}), 3.04-2.97(\mathrm{~m}, 1 \mathrm{H}), 2.81(\mathrm{~s}, 2 \mathrm{H}), 2.64(\mathrm{~d}, J=4.3 \mathrm{~Hz}$, $3 \mathrm{H}), 1.94(\mathrm{~s}, 2 \mathrm{H}) .{ }^{13} \mathrm{C}-\mathrm{NMR}\left(\mathrm{DMSO}_{6}\right) \delta 174.39,165.39,156.11,154.68,146.84,143.73$, $138.08,132.17,130.04,129.92,124.73,122.14,117.60,117.41,115.26(t, J=235 \mathrm{~Hz}), 113.78$, $112.92,94.46,49.07,46.13,42.44,35.45,30.35,26.68,23.44$. HPLC: retention time $11.429 \mathrm{~min}$, $96.29 \%$ purity (using formic acid instead of trifluoroacetic acid). HRMS (ESI): $\mathrm{m} / \mathrm{z}$ calcd for $\mathrm{C}_{25} \mathrm{H}_{24} \mathrm{~F}_{2} \mathrm{~N}_{4} \mathrm{O}_{5}, 499.1788$, found $499.1808[\mathrm{M}+\mathrm{H}]^{+}$.

3.1.26. 5-(1-Methyl-1H-pyrazol-4-yl)-3'-(2-oxo-2-(3-(trifluoromethyl)-5,6-dihydro$[1,2,4]$ triazolo[4,3-a]pyrazin-7(8H)-yl)ethyl)-2,3-dihydrospiro[indene-1,5'-oxazolidine]$2^{\prime}, 4^{\prime}$-dione (B18)

Prepared using the same procedure as for B15, except using 5-bromo-3'-(2-oxo-2-(3(trifluoromethyl)-5,6-dihydro-[1,2,4]triazolo[4,3-a]pyrazin-7(8H)-yl)ethyl)-2,3-dihydrospiro [indene-1,5'-oxazolidine]-2' $4^{\prime}$-dione $(\mathbf{1 0 1}, 0.10 \mathrm{~g}, 0.20 \mathrm{mmol})$ instead of 98 afforded B18 $(0.034 \mathrm{~g}, 33 \%) .{ }^{1} \mathrm{H}-\mathrm{NMR}\left(\mathrm{CDCl}_{3}\right) \delta 7.76(\mathrm{~s}, 1 \mathrm{H}), 7.62(\mathrm{~s}, 1 \mathrm{H}), 7.47(\mathrm{~d}, J=7.3 \mathrm{~Hz}, 1 \mathrm{H}), 7.43(\mathrm{~s}$, $1 \mathrm{H}), 7.26(\mathrm{~s}, 1 \mathrm{H}), 5.10-5.01(\mathrm{~m}, 2 \mathrm{H}), 4.61-4.47(\mathrm{~m}, 2 \mathrm{H}), 4.23(\mathrm{~s}, 1 \mathrm{H}), 4.16(\mathrm{~s}, 1 \mathrm{H}), 3.95(\mathrm{~s}$, $2 \mathrm{H}), 3.49(\mathrm{~s}, 3 \mathrm{H}), 3.34-3.23(\mathrm{~m}, 1 \mathrm{H}), 3.21-3.10(\mathrm{~m}, 1 \mathrm{H}), 2.89-2.78(\mathrm{~m}, 1 \mathrm{H}), 2.65-2.56$ $(\mathrm{m}, 1 \mathrm{H}) .{ }^{13} \mathrm{C}-\mathrm{NMR}\left(\mathrm{CDCl}_{3}\right) \delta 174.53,163.72,154.29,152.43,148.55,146.11,136.97,135.70$, 134.85, 129.458, 127.38, 124.77, 123.96 (q, $J=273 \mathrm{~Hz}), 94.93,43.31,43.09,41.74,40.96,39.20$, 35.42, 30.30, 12.33. HPLC: retention time $9.839 \mathrm{~min}, 96.11 \%$ purity (using formic acid instead of trifluoroacetic acid). HRMS (ESI): $m / z$ calcd for $\mathrm{C}_{23} \mathrm{H}_{20} \mathrm{~F}_{3} \mathrm{~N}_{7} \mathrm{O}_{4}, 516.1602$, found $516.1618[\mathrm{M}+\mathrm{H}]^{+}$.

\subsection{Cell Viability Assays}

The 22Rv1 prostate cancer cell line in this study was purchased from KeyGEN Biotech Co. Ltd. (Nanjing, Jiangsu, China ). The cells were cultured in RPMI 1640 medium and maintained at $37^{\circ} \mathrm{C}$ in a $5 \% \mathrm{CO}_{2}$ incubator. For the cell viability assay, the cell slurry was 
diluted to required volume at a density of 80,000 cells $/ \mathrm{mL}$. Then, $100 \mu \mathrm{L}$ the cell slurry was seeded in each well of the 96-well plate. The cells were incubated for $72 \mathrm{~h}$ at $37{ }^{\circ} \mathrm{C}, 5 \%$ $\mathrm{CO}_{2}$ under humidified condition. The reference and test compounds solution $(200 \times)$ were prepared with DMSO and were diluted from $200 \times$ to $1 \times$ with culture medium (RPMI 1640 medium without phenol red and containing $10 \%$ fetal calf serum, penicillin $(100 \mathrm{U} / \mathrm{mL})$, streptomycin $(100 \mu \mathrm{g} / \mathrm{mL})$ and $0.1 \mathrm{nM}$ DHT). The previous culture medium was removed and $200 \mu \mathrm{L} /$ well of the compound solution $(1 \times)$ was added to assay plate (final conc: $1 \times$ ). Then the cells were incubated at $37^{\circ} \mathrm{C}, 5 \% \mathrm{CO}_{2}$ under humidified conditions. 5 Days later, the CCK-8 assay reagent was equilibrated at room temperature for $30 \mathrm{~min}$ prior to use. CCK-8 was mixed with fresh medium at a ratio of $1: 10$ and $100 \mu \mathrm{L}$ of the diluted CCK8 reagent was added to each well and the plates were incubated for $4.5 \mathrm{~h}$ at $37^{\circ} \mathrm{C}$. Finally, absorbance value (OD value) was read on plate reader. GraphPad Prism v5.0 software was used to process data for $\mathrm{IC}_{50}$.

\subsection{Pharmacokinetics Procedures}

Pharmacokinetic experiments of test compounds were performed in male Balb/C mice similarly to our previous work [38]. The mice were randomly assigned to two groups and were administrated the test compound orally and intravenously, respectively. The test compounds were prepared into $0.5 \mathrm{mg} / \mathrm{mL}$ oral solution with $10 \% \mathrm{PG}, 10 \%$ ethanol, $10 \%$ solutol and $70 \%$ normal saline, or $0.1 \mathrm{mg} / \mathrm{mL}$ injection solution with $2 \% \mathrm{PG}, 2 \%$ ethanol, $2 \%$ solutol and $94 \%$ normal saline. After intravenous or oral administration, blood was collected from the orbital venous plexus into heparinized EP tube $(0.6 \mathrm{~mL})$ at $5,15,30 \mathrm{~min}$, $1,2,6,10$, and $24 \mathrm{~h}$, temporarily placed on crushed ice. Certain processing was performed on blood samples and testing samples were sent to LC-MS/MS for analysis.

\subsection{In Vivo Tumor Xenograft Model}

A well-established tumorigenesis assay was used to evaluate the antitumor effect of B16-P2 in male NOD-SCID mice model. All mice were raised in standard specificpathogen-free (SPF) environment. Mice were randomly allocated to three groups (6 mice in each group) by an independent person in the laboratory. No statistical method was used to predetermine sample size. $5 \times 10^{6} 22 \mathrm{Rv} 1$ cells (purchased from Nanjing KeyGEN Biotech Co. Ltd.) were injected subcutaneously into the NOD-SCID male mice at 5-to-6week-old (purchased from Shanghai lingchang animal Co. Ltd.). All compounds were prepared into solution using 5\% ethanol, 30\% PG, 25\% PEG400, 10\% solutol, and 30\% pure water successively and were administrated by oral gavage. Mice were examined thrice a week for the development of tumors by Vernier caliper and tumor volumes were calculated using the formula $\mathrm{V}=0.5 \times$ length $\times$ width $^{2}$. The investigators were not blinded to allocation during experiments and outcome assessment. The antitumor effects of the compounds were assessed by tumor growth inhibition (TGI) or relative tumor proliferation rate $(\mathrm{T} / \mathrm{C})$ : TGI $(\%)=\left[1-\left(\mathrm{V}_{\mathrm{t} 1}-\mathrm{V}_{\mathrm{t} 0}\right) /\left(\mathrm{V}_{\mathrm{c} 1}-\mathrm{V}_{\mathrm{c} 0}\right)\right] \times 100 \%$, where $\mathrm{V}_{\mathrm{c} 1}$ and $\mathrm{V}_{\mathrm{t} 1}$ are the mean volumes of control and treated groups at time of tumor extraction, while $\mathrm{V}_{\mathrm{c} 0}$ and $\mathrm{V}_{\mathrm{t} 0}$ are the same groups at the start of dosages; $\mathrm{T} / \mathrm{C}(\%)=\mathrm{T}_{\mathrm{RTV}} / \mathrm{C}_{\mathrm{RTV}} \times 100 \%$, where $\mathrm{T}_{\mathrm{RTV}}$ is the relative tumor volume (RTV) of treated groups, while $C_{R T V}$ is the RTV of control groups. $\left(\mathrm{RTV}=\mathrm{V}_{\mathrm{t}} / \mathrm{V}_{0}, \mathrm{~V}_{\mathrm{t}}\right.$ is the mean volumes of treated groups at time of tumor extraction, $\mathrm{V}_{0}$ is the mean volumes of the same groups at the start of dosages).

\subsection{Molecular Dynamic Simulation and Docking}

Molecular dynamic simulation was performed with Desmond in Schrodinger Maestro 2019 using OPLS_2005 as force field (PDB code: 5kj2). The systems were solvated in TIP3P water molecules in a truncated octahedron periodic box, then neutralized by adding $\mathrm{Na}+$ cations. After energy minimization, a sum of production simulation was performed for $100 \mathrm{~ns}$ using the NPT ensemble under a constant temperature of $300 \mathrm{~K}$ and pressure of $1 \mathrm{~atm}$. Other parameters were maintained at the default configuration. Finally, the binding free energies for the complexes were calculated by Prime/MM-GBSA module. Molecular 
docking was performed with Glide module in Schrodinger Maestro 2019, with OPLS_2005 as force field and Extra Precision (XP) as algorithm.

\section{Conclusions}

In summary, twenty-six new compounds based on the 2-(2',4'-dioxo-2,3-dihydrospiro [indene-1, $5^{\prime}$-oxazolidine]-3'-yl)acetamide scaffold were designed based on a bioisosterism and conformational restriction strategy. Their antiproliferative activities against enzalutamide resistant prostate cancer $22 \mathrm{Rv} 1$ cell were evaluated. A comprehensive SAR study was concluded, leading to the strongest inhibitor B16. Molecular docking predicted the possible binding mode with p300 HAT domain. The additional hydrogen bond between chromane oxygen of B16 and HAT protein was of critical importance for the observed stronger activity. Furthermore, compound B16 exhibited suitable PK properties. The in vivo 22Rv1 xenograft model revealed that compound B16-P2 inhibited tumor growth stronger than A-485 at the same dosage. In general, our results suggest that these spirocyclic chromane derivatives were a class of promissing therapeutic agents of prostate cancer for further optimization.

Supplementary Materials: The following are available online. Experimental procedures for preparation of compounds, chemical spectrum and purity determination.

Author Contributions: Conceptualization, L.Z. and Y.W.; methodology, Y.W., S.Y. (Shengwei Yang); experiments and data curation, L.F., S.Y. (Shujia Yu), H.W., S.Y. (Shengwei Yang), X.L., H.D.; writingoriginal draft preparation, Y.W.; writing—review and editing, Y.W.; supervision, C.J. and Y.W.; project administration, L.Z. All authors have read and agreed to the published version of the manuscript.

Funding: This research received no external funding.

Institutional Review Board Statement: The study was conducted according to the guidelines of the Declaration of Helsinki, and approved by the Institutional Review Board.

Informed Consent Statement: Not applicable.

Data Availability Statement: Not applicable.

Conflicts of Interest: The author declares no conflict of interest.

Sample Availability: Samples of the compounds are available from the authors.

\section{References}

1. Jones, P.A.; Baylin, S.B. The epigenomics of cancer. Cell 2007, 128, 683-692. [CrossRef] [PubMed]

2. Haberland, M.; Montgomery, R.; Olson, E. The many roles of histone deacetylases in development and physiology: Implications for disease and therapy. Nat. Rev. Genet. 2009, 10, 32-42. [CrossRef] [PubMed]

3. Tessarz, P.; Kouzarides, T. Histone core modifications regulating nucleosome structure and dynamics. Nat. Rev. Mol. Cell. Biol. 2014, 15, 703-708. [CrossRef] [PubMed]

4. Wu, J.; Xie, N.; Wu, Z.; Zhang, Y.; Zheng, Y.G. Bisubstrate inhibitors of the MYST HATs Esa1 and Tip60. Bioorg. Med. Chem. 2009, 17, 1381-1386. [CrossRef]

5. Farria, A.; Li, W.; Dent, S. KATs in cancer: Functions and therapies. Oncogene 2015, 34, 4901-4913. [CrossRef]

6. Valor, L.M.; Viosca, J.; Lopez-Atalaya, J.P.; Barco, A. Lysine acetyltransferases cbp and p300 as therapeutic targets in cognitive and neurodegenerative disorders. Curr. Pharm. Design 2013, 19, 5051-5064. [CrossRef]

7. Roche, J.; Bertrand, P. Inside HDACs with more selective HDAC inhibitors. Eur. J. Med. Chem. 2016, 121, 451-483. [CrossRef]

8. Bedford, D.C.; Kasper, L.H.; Fukuyama, T.; Brindle, P.K. Target gene context influences the transcriptional requirement for the KAT3 family of CBP and p300 histone acetyltransferases. Epigenetics 2010, 5, 9-15. [CrossRef]

9. Iyer, N.G.; Özdag, H.; Caldas, C. p300/CBP and cancer. Oncogene 2004, 23, 4225-4231. [CrossRef]

10. Kalkhoven, E. CBP and p300: HATs for different occasions. Biochem. Pharmacol. 2004, 68, 1145-1155. [CrossRef]

11. Vo, N.; Goodman, R.H. CREB-binding protein and p300 in transcriptional regulation. J. Biol. Chem. 2001, 276, 13505-13508. [CrossRef]

12. Ogryzko, V.V.; Schiltz, R.L.; Russanova, V.; Howard, B.H.; Nakatani, Y. The transcriptional coactivators p300 and CBP are histone acetyltransferases. Cell 1996, 87, 953-959. [CrossRef]

13. Zeng, L.; Zhang, Q.; Gerona-Navarro, G.; Moshkina, N.; Zhou, M.M. Structural basis of site-specific histone recognition by the bromodomains of human coactivators PCAF and CBP/p300. Structure 2008, 16, 643-652. [CrossRef]

14. Kouzarides, T. Chromatin modifications and their function. Cell 2007, 128, 693-705. [CrossRef] 
15. Wang, L.; Gural, A.; Sun, X.J.; Zhao, X.; Perna, F.; Huang, G.; Hatlen, M.A.; Vu, L.; Liu, F.; Xu, H.; et al. The leukemogenicity of AML1-ETO is dependent on site-specific lysine acetylation. Science 2011, 333, 765-769. [CrossRef]

16. Liu, Y.; Wang, L.; Predina, J.; Han, R.; Beier, U.H.; Wang, L.C.; Kapoor, V.; Bhatti, T.R.; Akimova, T.; Singhal, S.; et al. Inhibition of p300 impairs Foxp3(+) T regulatory cell function and promotes antitumor immunity. Nat. Med. 2013, 19, 1173-1177. [CrossRef]

17. Lau, O.D.; Kundu, T.K.; Soccio, R.E.; Ait-Si-Ali, S.; Khalil, E.M.; Vassilev, A.; Khalil, Y.N.; Wolffe, A.P.; Roeder, R.G.; Cole, P.A. HATs off: Selective synthetic inhibitors of the histone acetyltransferases p300 and PCAF. Mol. Cell 2000, 5, 589-595. [CrossRef]

18. Arif, M.; Pradhan, S.K.; GR, T.; Vedamurthy, B.M.; Agrawal, S.; Dasgupta, D.; Kundu, T.K. Mechanism of p300 specific histone acetyltransferase inhibition by small molecules. J. Med. Chem. 2009, 52, 267-277. [CrossRef]

19. Bowers, E.M.; Yan, G.; Mukherjee, C.; Orry, A.; Wang, L.; Holbert, M.A.; Cole, P.A. Virtual ligand screening of the p300/CBP histone acetyltransferase: Identification of a selective small molecule inhibitor. Chem. Biol. 2010, 17, 471-482. [CrossRef]

20. Shrimp, J.H.; Sorum, A.W.; Garlick, J.M.; Guasch, L.; Nicklaus, M.C.; Meier, J.L. Characterizing the covalent targets of a small molecule inhibitor of the lysine acetyltransferase p300. ACS Med. Chem. Lett. 2016, 7, 151-155. [CrossRef]

21. Lasko, L.M.; Jakob, C.G.; Edalji, R.P.; Qiu, W.; Montgomery, D.; Digiammarino, E.L.; Bromberg, K.D. Discovery of a selective catalytic p300/CBP inhibitor that targets lineage-specific tumours. Nature 2017, 550, 128-132. [CrossRef]

22. Wang, R.; He, Y.; Robinson, V.; Yang, Z.; Hessler, P.; Lasko, L.M.; Lu, X.; Bhathena, A.; Lai, A.; Uziel, T.; et al. Targeting Lineage-specific MITF pathway in human melanoma cell lines by A-485, the selective small-molecule inhibitor of p300/CBP. Mol. Cancer Ther. 2018, 17, 2543-2550. [CrossRef]

23. Zhang, X.; Zegar, T.; Lucas, A.; Morrison-Smith, C.; Knox, T.; French, C.A.; Knapp, S.; Muller, S.; Siveke, J.T. Therapeutic targeting of p300/CBP HAT domain for the treatment of NUT midline carcinoma. Oncogene 2020, 39, 4770-4779. [CrossRef]

24. Zhou, F.; Liu, Q.; Zhang, L.; Zhu, Q.; Wang, S.; Zhu, K.; Deng, R.; Liu, Y.; Yuan, G.; Wang, X.; et al. Selective inhibition of CBP/p300 HAT by A-485 results in suppression of lipogenesis and hepatic gluconeogenesis. Cell Death Dis. 2020, 11, 745. [CrossRef]

25. Peng, J.; Li, J.; Huang, J.; Xu, P.; Huang, H.; Liu, Y.; Yu, L.; Yang, Y.; Zhou, B.; Jiang, H.; et al. p300/CBP inhibitor A-485 alleviates acute liver injury by regulating macrophage activation and polarization. Theranostics 2019, 9, 8344-8361. [CrossRef]

26. Yang, Y.; Zhang, R.; Li, Z.; Mei, L.; Wan, S.; Ding, H.; Chen, Z.; Xing, J.; Feng, H.; Han, J.; et al. Discovery of highly potent, selective, and orally efficacious p300/CBP histone acetyltransferases inhibitors. J. Med. Chem. 2020, 63, 1337-1360. [CrossRef]

27. Wilson, J.E.; Patel, G.; Patel, C.; Brucelle, F.; Huhn, A.; Gardberg, A.S.; Poy, F.; Cantone, N.; Bommi-Reddy, A.; Sims, R.J.; et al. Discovery of CPI-1612: A potent, selective, and orally bioavailable EP300/CBP histone acetyltransferase inhibitor. ACS Med. Chem. Lett. 2020, 11, 1324-1329. [CrossRef]

28. Wilson, J.E.; Huhn, A.; Gardberg, A.S.; Poy, F.; Brucelle, F.; Vivat, V.; Patel, G.; Patel, C.; Cummings, R.; Sims, R.; et al. Early drug-discovery efforts towards the identification of EP300/CBP histone acetyltransferase (HAT) inhibitors. Chem. Med. Chem. 2020, 15, 955-960. [CrossRef]

29. Lu, W.; Xiong, H.; Chen, Y.; Wang, C.; Zhang, H.; Xu, P.; Han, J.; Xiao, S.; Ding, H.; Chen, Z.; et al. Discovery and biological evaluation of thiobarbituric derivatives as potent p300/CBP inhibitors. Bioorg. Med. Chem. 2018, 26, 5397-5407.

30. Liu, R.; Zhang, Z.; Yang, H.; Zhou, K.; Geng, M.; Zhou, W.; Zhang, M.; Huang, X.; Li, Y. Design, synthesis, and biological evaluation of a new class of histone acetyltransferase p300 inhibitors. Eur. J. Med. Chem. 2019, 180, 171-190. [CrossRef]

31. He, Z.X.; Wei, B.F.; Zhang, X.; Gong, Y.P.; Ma, L.Y.; Zhao, W. Current development of CBP/p300 inhibitors in the last decade. Eur. J. Med. Chem. 2021, 209, 112861. [CrossRef] [PubMed]

32. Kuca, K.; Musilek, K.; Jun, D.; Zdarova-Karasova, J.; Nepovimova, E.; Soukup, O.; Hrabinova, M.; Mikler, J.; Franca, T.C.C.; Da Cunha, E.F.F.; et al. A newly developed oxime K203 is the most effective reactivator of tabun-inhibited acetylcholinesterase. BMC Pharmacol. Toxicol. 2018, 19, 8. [CrossRef] [PubMed]

33. De Lima, W.E.A.; Pereira, A.F.; De Castro, A.A.; Da Cunha, E.F.F.; Ramalho, T.C. Flexibility in the molecular design of acetylcholinesterase reactivators: Probing representative conformations by chemometric techniques and docking/QM calculations. Lett. Drug Des. Discov. 2016, 13, 360-371. [CrossRef]

34. Wang, E.; Sun, H.; Wang, J.; Wang, Z.; Liu, H.; Zhang, J.Z.H.; Hou, T. End-Point Binding Free Energy Calculation with MM/PBSA and MM/GBSA: Strategies and Applications in Drug Design. Chem. Rev. 2019, 119, 9478-9508. [CrossRef]

35. Shiota, M.; Dejima, T.; Yamamoto, Y.; Takeuchi, A.; Imada, K.; Kashiwagi, E.; Inokuchi, J.; Tatsugami, K.; Kajioka, S.; Uchiumi, T.; et al. Collateral resistance to taxanes in enzalutamide-resistant prostate cancer through aberrant androgen receptor and its variants. Cancer Sci. 2018, 109, 3224-3234. [CrossRef]

36. Sramkoski, R.M.; Pretlow, T.G., 2nd; Giaconia, J.M.; Pretlow, T.P.; Schwartz, S.; Sy, M.S.; Marengo, S.R.; Rhim, J.S.; Zhang, D.; Jacobberger, J.W. A new human prostate carcinoma cell line, 22Rv1. In Vitro Cell Dev. Biol. Anim. 1999, 35, 403-409. [CrossRef]

37. Hogg, S.J.; Beavis, P.A.; Dawson, M.A.; Johnstone, R.W. Targeting the epigenetic regulation of antitumour immunity. Nat. Rev. Drug. Discov. 2020, 19, 776-800. [CrossRef]

38. Xu, G.; Zhang, Y.; Wang, H.; Guo, Z.; Wang, X.; Li, X.; Chang, S.; Sun, T.; Yu, Z.; Xu, T.; et al. Synthesis and biological evaluation of 4-(pyridin-4-oxy)-3-(3,3-difluorocyclobutyl)-pyrazole derivatives as novel potent transforming growth factor- $\beta$ type 1 receptor inhibitors. Eur. J. Med. Chem. 2020, 198, 112354. [CrossRef] 